\title{
Brain pathology in myotonic dystrophy: when tauopathy meets spliceopathy and RNAopathy
}

\author{
Marie-Laure Caillet-Boudin ${ }^{1,2 *}$, Francisco-Jose Fernandez-Gomez ${ }^{1,2}$, Hélène Tran ${ }^{1,2 \dagger}$, \\ Claire-Marie Dhaenens ${ }^{1,2}$, Luc Buee ${ }^{1,2}$ and Nicolas Sergeant ${ }^{1,2}$ \\ Alzheimer and Tauopathies, Faculty of Medicine, Jean-Pierre Aubert Research Centre, Institute of Predictive Medicine and Therapeutic Research, Inserm, UMR \\ 837, Lille, France \\ 2 University of Lille Nord de France, UDSL, Lille, France
}

\section{Edited by:}

Nicola Maggio, The Chaim Sheba

Medical Center, Israel

Reviewed by:

Herman Moreno, Columbia

University Medical School, USA

Nicola Maggio, The Chaim Sheba

Medical Center, Israel

*Correspondence:

Marie-Laure Caillet-Boudin,

Alzheimer and Tauopathies,

Jean-Pierre Aubert Research Centre

Institute of Predictive Medicine and

Therapeutic Research, Inserm,

UMR 837, 1 place de Verdun, 59045

Lille, France

e-mail: marie-laure.caillet@inserm.fr

${ }^{\dagger}$ Present address:

Hélène Tran, University of

Massachusetts Medical School,

Worcester, USA
Myotonic dystrophy (DM) of type 1 and 2 (DM1 and DM2) are inherited autosomal dominant diseases caused by dynamic and unstable expanded microsatellite sequences (CTG and CCTG, respectively) in the non-coding regions of the genes DMPK and ZNF9, respectively. These mutations result in the intranuclear accumulation of mutated transcripts and the mis-splicing of numerous transcripts. This so-called RNA gain of toxic function is the main feature of an emerging group of pathologies known as RNAopathies. Interestingly, in addition to these RNA inclusions, called foci, the presence of neurofibrillary tangles (NFT) in patient brains also distinguishes DM as a tauopathy. Tauopathies are a group of nearly 30 neurodegenerative diseases that are characterized by intraneuronal protein aggregates of the microtubule-associated protein Tau (MAPT) in patient brains. Furthermore, a number of neurodegenerative diseases involve the dysregulation of splicing regulating factors and have been characterized as spliceopathies. Thus, myotonic dystrophies are pathologies resulting from the interplay among RNAopathy, spliceopathy, and tauopathy. This review will describe how these processes contribute to neurodegeneration. We will first focus on the tauopathy associated with DM1, including clinical symptoms, brain histology, and molecular mechanisms. We will also discuss the features of DM1 that are shared by other tauopathies and, consequently, might participate in the development of a tauopathy. Moreover, we will discuss the determinants common to both RNAopathies and spliceopathies that could interfere with tau-related neurodegeneration.

Keywords: RNAopathy, tauopathy, splicing, myotonic dystrophy, Alzheimer's disease

\section{INTRODUCTION}

Myotonic dystrophy (DM) of type I (DM1), which is also referred to as dystrophia myotonica or Steinert's disease, is the most common form of adult-onset muscular dystrophy and affects at

\footnotetext{
Abbreviations: $3^{\prime}$ UTR, $3^{\prime}$ untranslated region; $\mathrm{A} \beta$, amyloid beta; $\mathrm{AD}$, Alzheimer's disease; ALS, amyotrophic lateral sclerosis; APP, amyloid- $\beta$ precursor protein; $\mathrm{BBB}$, blood-brain barrier; Bin-1, bridging integrator-1; CBD, corticobasal degeneration; CELF, CUG-BP and ETR-3-like factor; CELF1, CUG-binding protein 1 (CUG-BP1); CELF2, CUGBP2 or ETR-3; CNS, central nervous system; CSF, cerebrospinal fluid; DLB, dementia with Lewy bodies; DM, myotonic dystrophy; DM1, myotonic dystrophy of type 1; DM2, myotonic dystrophy of type 2; DMPK, myotonic dystrophy protein kinase; DS, Down syndrome; EDS, excessive daytime sleepiness; FAT, fast anterograde transport; FISH, fluorescence in situ hybridization; FTD, frontotemporal dementia; FTDP-17, frontotemporal dementia and parkinsonism linked to chromosome 17; FUS, fused in sarcoma; GVD, granulovacuolar degeneration; $h n R N P$, heterogeneous nuclear ribonucleoprotein; IR, insulin resistance; IRES, internal ribosome entry site; KO, Knockout; LB, Lewy bodies; MAPT, microtubule-associated protein tau; MB, Marinesco bodies; MBNL, Muscleblind-like; MBR, microtubule-binding repeats; MRI, magnetic resonance imaging; NFD, neurofibrillary degeneration; NFT, neurofibrillary tangle; NMDAR, N-methyl-D-aspartate receptors; ORF, open reading frame; PAD, phosphatase activating domain; PD, Parkinson's disease; PiD, Pick's disease; PRD, proline-rich domain; PROMM, proximal myotonic myopathy; PS, presenilin; PSP, progressive supranuclear palsy; RAN, Repeat-associated non-ATG-initited translation; RBP, RNA-binding proteins; SMA, spinal muscular atrophy; SMN, survival of motor neurons; SNPs, single nucleotide polymorphisms; snRNP, small nuclear ribonucleoprotein; T2DM, type II diabetes; TDP-43, TAR DNA-binding protein 43.
}

least 1 in 8000 people worldwide. DM1 is an inherited autosomal dominant disease caused by the dynamic and unstable expansion of a trinucleotide CTG repeat motif in the $3^{\prime}$ UTR of the $D M P K$ gene located at q13.3 on chromosome 19 (Brook et al., 1992). Affected individuals carry CTG copy numbers greater than 50 and present a highly variable phenotype, ranging from asymptomatic to a severe congenital form of the disease. The length of CTG expansion has been associated with the severity of the pathology and is dependent on both meiotic and somatic instability (Mahadevan et al., 1992; Harley et al., 1993; Wong et al., 1995; Martorell et al., 1998). This inherited neuromuscular disease affects multiple organs, including skeletal and smooth muscles (distal muscular atrophy, myotonia, muscle weakness grip and wasting, percussion myotonia hatchet face, and ptosis), the heart (arrhythmia and conduction defects), the endocrine system (hyperinsulinemia), eyes (cataracts), gonads (atrophy), the central nervous system (CNS) (executive and visuoconstructive difficulties, facial emotion recognition impairment, and neuropsychiatric symptoms), and the peripheral nervous system (axonal peripheral neuropathy) (cf reviews: Schara and Schoser, 2006; Turner and Hilton-Jones, 2010; Romeo, 2012).

The mechanisms underlying DM1 physiopathology have recently begun to be elucidated. DM1 is the first identified disease 
resulting from a repeat expansion in a non-coding region of mRNA. Thus, the toxic effect of the CTG expansion seems to be more associated with the expression of mutated DMPK RNA than with changes in the expression of the DMPK protein. Substantial evidence supports a pathogenic role for these non-coding repeats at the RNA level, such as the discovery of a second type of DM, DM2 (or PROMM, proximal myotonic myopathy), which is due to a CCTG repeat expansion in another non-coding part of another transcript, the first intron of the ZNF9 gene (Liquori et al., 2001). The nuclear export of the mutated RNAs is defective, and they subsequently accumulate and aggregate to form socalled nuclear foci, which then recruit and sequester RNA-binding proteins (RBP) [reviewed in Day and Ranum (2005), Schoser and Timchenko (2010)]. The identification of new pathologies presenting a similar RNA toxicity associated with repeat expansions, foci appearance, and the sequestration of RBP led to the identification of these disorders as RNAopathies (Renoux and Todd, 2012). The subsequent loss of function of these RBP leads to a disruption in RNA metabolism, including modifications of the alternative splicing of numerous pre-messenger RNAs in several tissues. This altered process highly contributes to the multisystemic effect of the DM1 mutation [reviewed in Kuyumcu-Martinez and Cooper (2006); Ranum and Cooper (2006)]. Other mechanisms might interfere with pathology development. The haploinsufficiency of the protein encoded by the mutated allele and the cis-effect of the mutation on neighboring genes have been explored (Fu et al., 1993; Novelli et al., 1993; Otten and Tapscott, 1995; Thornton et al., 1997). More recently, the mutation in DM1 has been suggested to have additional effects on the translation and stability of proteins, generation of toxic anti-sense transcripts, and expression of toxic homopolymeric peptide species through a non-ATG initiated translation pathway [recently reviewed in Klein et al. (2011), Sicot et al. (2011)].

Interest in the neurological aspects of DM has increased in the last several years. Reviews and workshops of these studies have primarily focused on clinical symptoms and neuroimaging (Axford and Pearson, 2013). This review highlights a particular aspect of DM neurological disorders, the tauopathy. Tauopathies are neurodegenerative diseases characterized by the intraneuronal aggregation of microtubule-binding Tau proteins. The aim of this review is to describe the different aspects of the Tau pathology observed in DM1, including clinical symptoms, brain histology, and molecular mechanisms. We will also discuss the features of DM1 that are shared by other tauopathies and neurodegenerative diseases and that might contribute to the development of tauopathies. Moreover, we will focus on the possible interactions between the mechanisms of RNAopathy, spliceopathy, and tauopathy in the development of DM brain pathology.

\section{DM NEUROPATHOLOGICAL SIGNS AND TAUOPATHY FEATURES \\ CLINICAL SYMPTOMS}

Cognitive impairment in DM1 has been clearly established. DM1 patients exhibit changes in personality traits and/or mood disorders (Rubinsztein et al., 1998; Meola et al., 2003; Antonini et al., 2006; Winblad et al., 2006b). The cerebral involvement of DM1 patients has been associated with difficulties in executive functions (D'Angelo and Bresolin, 2003), visuospatial/constructive abilities (Malloy et al., 1990), memory (Rubinsztein et al., 1997), facial emotion recognition (Winblad et al., 2006a), and psychomotor delay. Apathy (Rubinsztein et al., 1998), avoidance (Meola et al., 2003), depression and anxiety (Antonini et al., 2006), anhedonia, and decreased emotional participation are often the main neurological and clinical symptoms of this pathology (Bungener et al., 1998). Approximately one third of DM1 patients also suffer from excessive daytime sleepiness (EDS) that most likely results from CNS disturbance [reviewed in Laberge et al. (2013)]. Consistent with this observation, MBNL2 $\mathrm{KO}$ transgenic mice, which are characterized by neurodegenerative symptoms in the absence of obvious muscle alterations, develop hypersomnia (Charizanis et al., 2012). In the most severe cases of DM1 (congenital/juvenile form), mental retardation has also been described [reviewed in Machuca-Tzili et al. (2005); Schara and Schoser (2006)]. Furthermore, approximately half of these young patients also have autism spectrum disorders, the frequency of which is related to the number of CTG repeat (Ekstrom et al., 2008).

Brain involvement in DM2 is more controversial. Similar cognitive and behavioral dysfunctions are described, with milder manifestations compared with DM1 (Meola et al., 2003; Weber et al., 2010). In contrast to DM1, DM2 has not been associated with developmental abnormalities and thus does not cause severe childhood symptoms. This difference likely explains why no mental retardation similar to that reported in congenital and juvenile forms of DM1 has been described in DM2 patients.

\section{NEUROIMAGING}

MRI studies have revealed global cerebral atrophy with dilated ventricles in DM1 (Censori et al., 1994; Antonini et al., 2004). No correlation has been observed between brain tissue volumes and the grade of pathology, disease duration, or CTG expansion. However, the potential correlation between brain tissue volume and CTG expansion remains unclear because these studies were performed using repeat lengths measured from blood cells and not from brain tissue, where the somatic instability of CTG expansion is particularly obvious and varies both with a single brain area and between different areas. Indeed, the expansion length can vary from 150 to more than 3000 CTG repeats (Sergeant et al., 2001; Dhaenens et al., 2011). Furthermore, a large difference in the CTG expansion length between muscle and blood has recently been reported, confirming that the CTG length depends on the tissue analyzed (Nakamori et al., 2013). Thus, the potential correlation between brain imaging alterations and CTG repeat length in the altered regions remains unclear. Future follow-up clinical studies are needed to support a correlation.

In DM1, cortical gray matter loss is primarily observed in the frontal, parietal, and occipital regions and in the superior and middle temporal gyrus, whereas subcortical gray matter loss is detected in thalamic and basal ganglia structures (Antonini et al., 2004; Weber et al., 2010; Minnerop et al., 2011). These areas are involved in cognitive dysfunctions and personality disorders, such as apathy, depression, anxiety, and deficits in attention, memory, and visuospatial function (Antonini et al., 2004). Cortical atrophy has also been observed in DM2, although to a lesser 
extent than in DM1 (Ota et al., 2006; Minnerop et al., 2008, 2011).

White matter lesions are more pronounced than gray matter lesions in the DM1 brain. Regression analyses have revealed associations between affected white matter and several clinical parameters in both DM1 and DM2, but no associations with neuropsychological performance have been described (Minnerop et al., 2011). A recent study of children and adolescents suggested a relationship between white matter damage and working memory (Wozniak et al., 2013). White matter lesions are detected throughout the whole brain in DM types 1 and 2, affecting association fibers, commissural fibers (primarily in the corpus callosum), and projection fibers in the brainstem and the internal and external capsules, which connect the prefrontal and temporal cortical areas with the striatum. Although white matter lesions are also present in the frontal regions of patient brains, lesions located within anterior temporal lobes are considered a characteristic feature in DM patients (Hund et al., 1997; Di Costanzo, 2001; Naka et al., 2002; Kassubek et al., 2003; Kornblum et al., 2004; Fukuda et al., 2005; Vielhaber et al., 2006; Minnerop et al., 2011). These lesions demonstrate familial aggregation in DM1 and could be progressive along the disease evolution in association with CTG length (Di Costanzo, 2001; Ota et al., 2006; Romeo et al., 2010; Minnerop et al., 2011). Moreover, "état criblé" in the cerebral deep white matter has recently been reported (Itoh et al., 2010). Furthermore, hypoperfusion and glucose hypometabolism in the frontal and temporal lobes have been observed in DM, although these features are present to a greater extent in the DM1 brain than in the DM2 brain (Meola et al., 1999; Weber et al., 2010).

\section{HISTOLOGY \\ Foci}

Mutated DMPK transcripts with abnormally expanded CUG repeats are retained and accumulated in RNA nuclear inclusions called foci, which were first observed in DM1 muscle biopsies (Taneja et al., 1995). These foci have also been observed in human DM1 brains, particularly in the neuronal cells of the cerebral cortex, hippocampus, dentate gyrus, thalamus, substantia nigra, and brain stem tegmentum. A weak detection of foci has also been reported in the oligodendrocytes of the subcortical white matter and corpus callosum (Jiang et al., 2004). These nuclear RNA inclusions sequester RNA-binding proteins, such as the splicing factors Muscleblind-like 1 (MBNL1) and MBNL2 (Miller et al., 2000; Fardaei et al., 2001, 2002; Jiang et al., 2004) and to a lesser extent, heterogeneous nuclear ribonucleoproteins (hnRNPs) H and F (Jiang et al., 2004; Kim et al., 2005; Paul et al., 2011). While hnRNP H has been suggested to prevent the nuclear export of the mutated transcripts, MBNL1 has been directly implicated in the formation and stabilization of foci [(Kim et al., 2005; Querido et al., 2011); detailed below]. Interestingly, focus formation has also been observed in the brains of transgenic DMSXL mice bearing more than 1000 CTG repeats (Huguet et al., 2012) and in neuronal progeny derived from human embryonic stem cells carrying the DM1 mutation, particularly neuronal cells with a motor neuron phenotype (Marteyn et al., 2011).

\section{Neurofibrillary degeneration (NFD)}

NFD is an age-related process that occurs during normal aging and is abnormally enhanced in neurodegenerative diseases referred to as "tauopathies". NFD is characterized by the accumulation of intraneuronal argyrophilic fibers. This insoluble material corresponds to the accumulation and aggregation of hyperphosphorylated microtubule-associated Tau proteins, which form neurofibrillary tangles (NFTs) [reviewed in Buee et al. (2010)], mainly in neuron soma but also in neuropile threads, similarly to that observed in an AD brain, whereas Tau proteins of a healthy neuron are mainly located in the axon. First identified in the brains of Alzheimer's disease (AD) patients, NFD is now considered a common neuronal feature in nearly 30 tauopathies [reviewed in Sergeant et al. (2008)]. The spatiotemporal progression of the neurofibrillary lesions through the brains of $\mathrm{AD}$ patients can be subdivided in 6 or 10 stages according to the anatomopathological description of Braak and Braak (1991) or the biochemical analysis of more than 20 brain regions from 200 individuals, respectively (Delacourte et al., 1999). The density and topographic progression of NFTs have been correlated with disease severity and cognitive decline in AD patients (Duyckaerts et al., 1997; Berg et al., 1998; Giannakopoulos et al., 2003; Bennett et al., 2004). This observation strongly suggests a central role for fibrillar Tau inclusions in the pathophysiology and clinical symptoms of AD. Furthermore, the propagation of Tau pathology has recently been reported in animals after the injection of insoluble material obtained from animal models of $\mathrm{AD}$, the brains of $\mathrm{AD}$ patients, or a lentivirus encoding wild type Tau (Clavaguera et al., 2009, 2013; De Calignon et al., 2012; Lasagna-Reeves et al., 2012; Caillierez et al., 2013).

This relationship between Tau inclusion and pathophysiology is supported by the identification of autosomal dominant mutations in the MAPT gene in various other tauopathies, such as fronto-temporal dementia (FTD); these mutations are sufficient to induce both clinical symptoms and Tau pathology [reviewed in Schraen-Maschke et al. (2008), Umeda et al. (2013)].

Is the cognitive dysfunction reported in DM1 associated with the development of a tauopathy? Indeed, NFTs have been observed in both DM1 and DM2 brains in the amygdala, CA1, hippocampus, entorhinal cortex, and temporal cortex, then with a topographic distribution similar to that reported for moderate Alzheimer disease although the topographic progression of Tau pathology during DM1 has not yet been clearly established (Figure 1) (Yoshimura et al., 1990; Vermersch et al., 1996; Delacourte et al., 1999; Maurage et al., 2005). Thus, DM can be considered as a tauopathy-associated disease solely based on the presence of NFTs (Yoshimura et al., 1990; Vermersch et al., 1996; Sergeant et al., 2001; Maurage et al., 2005; Oyamada et al., 2006; Itoh et al., 2010). Although a lower distribution of Tau inclusions throughout the brain is observed in DM patients compared with other pathologies, such as $\mathrm{AD}$, the topographic distribution and expression of NFTs are still higher than that in unaffected individuals of the same age (Vermersch et al., 1996). Tau pathology progression in the DM brain is therefore considered moderate and is close to Braak and Braak stage 3-4 based on the number of NFTs observed. 


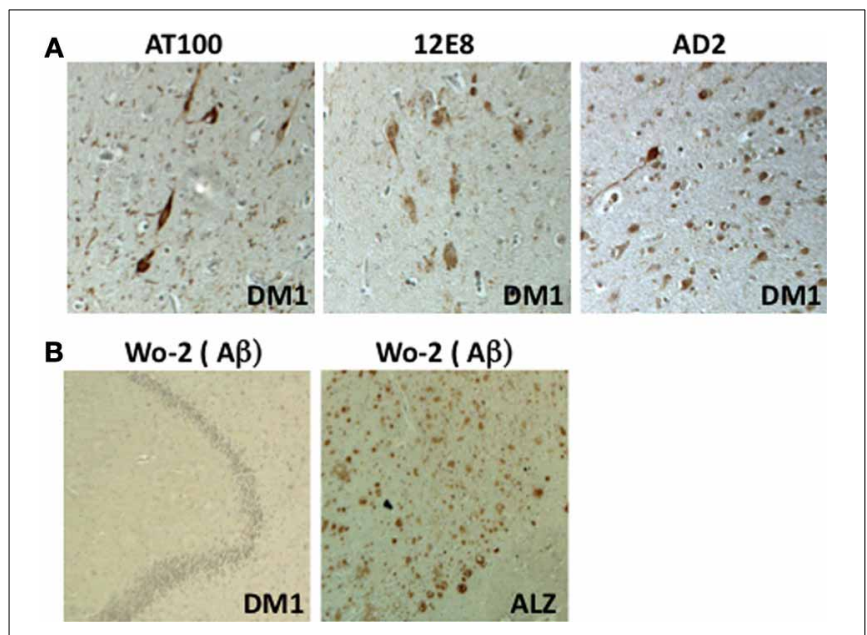

FIGURE 1 | Immunohistochemical analysis of the DM1 hippocampus (CA1 region). (A) Detection of NFTs using three antibodies directed against Tau phosphorylated Ser202-205 (AT8), phosphorylated Ser 262 (12E8), and phosphorylated Ser396-404 (AD2) (x200). (B) Absence of amyloid detection using the Wo-2 antibody in samples obtained from individuals with DM1 (x100). Positive control: AD brain (Alz) (x100).

Although all tauopathies are characterized by intraneuronal Tau aggregates, their clinical symptoms and histopathological criteria differ, including the structure of the aggregates (paired helical filaments, straight filaments or Pick bodies), the cerebral localization of degenerating neurons, the presence or absence of glial Tau inclusions (astrocytic plaques, tuft-shaped astrocytes, and oligodendroglial coiled bodies), and the association with other types of neuropathological lesions, such as extracellular amyloid deposits or Lewy bodies (LBs) [reviewed in Sergeant et al. (2005)]. In DM1 brains, no amyloid/senile plaques have been described (Figure 1), and $\alpha$-synuclein inclusions (LBs) have scarcely been observed (Kiuchi et al., 1991; James et al., 2012) (Maurage and Sergeant, unpublished results). DM is therefore different from AD or dementia with Lewy bodies (DLB) (Kiuchi et al., 1991). However, as in many age-related neurodegenerative disorders, a strong gliosis has been observed (Yoshimura et al., 1990; Ono et al., 1995). Although neurodegenerating neurons typically contain NFTs, the ultrastructure of these DM Tau aggregates remains unknown.

The aggregate composition in Tau isoforms permits the classification of the different tauopathies into five sub-groups (reviewed in Sergeant et al., 2005). In the human adult brain, six Tau protein isoforms are expressed through alternative splicing of exons 2, 3, and 10 (Figures 2, 3). These isoforms are named according to their splicing patterns: $2 \mathrm{~N} 3 \mathrm{R}, 1 \mathrm{~N} 3 \mathrm{R}, 0 \mathrm{~N} 3 \mathrm{R}, 2 \mathrm{~N} 4 \mathrm{R}$, $1 \mathrm{~N} 4 \mathrm{R}$, and $0 \mathrm{~N} 4 \mathrm{R}$. Two other minor exons, $4 \mathrm{~A}$ and 6 , have also been detected in mature brain RNA, but the levels of these transcripts are low, and the corresponding proteins are not detected in the brain. Depending on the disease, the Tau protein isoform composition varies. All six Tau isoforms are aggregated in some diseases, such as $\mathrm{AD}$, whereas the preferential aggregation of $3 \mathrm{R}$ or $4 \mathrm{R}$ isoforms occurs in other diseases, such as Pick's disease (PiD) and progressive supranuclear palsy (PSP), respectively [reviewed

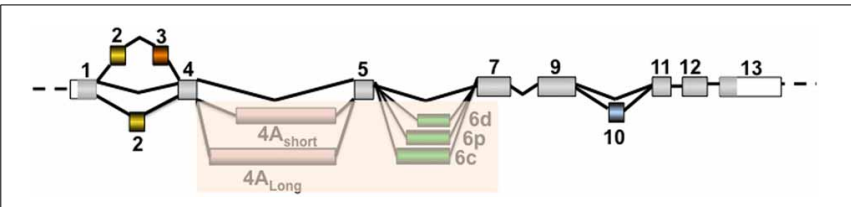

FIGURE 2 | Different splicing patterns of Tau- alternative exons leading to the main expression of six isoforms in the adult brain: 2N3R, 1N3R, ON3R, 2N4R, 1N4R, and 0N4R. The isoforms $0 \mathrm{~N}, 1 \mathrm{~N}$, and $2 \mathrm{~N}$ correspond to the exclusion or inclusion of only exon 2 or both exons 2 and 3 . Note that exon 3 insertion is dependent on exon 2 insertion. The isoforms $3 R$ and $4 R$ correspond to the exclusion or inclusion of exon 10, respectively. Note that this figure only indicates the alternative splicing of coding exons. The coding regions are colored in gray for constitutive exons and in yellow, orange, pale purple, green, and blue for alternative exons $2,3,4 \mathrm{~A}, 6$, and 10 , respectively. The inclusion of exons $4 A$ and 6 occurs rarely in the brain and is more prominently detected in the peripheral nervous system, and the insertion of these exons varies according to the $3^{\prime}$ splicing site used. These two exons are shaded because the corresponding protein isoforms are not detected in the brain.

in Sergeant et al. (2005)]. DM is the only disease characterized by the preferential aggregation of a single isoform: the smaller $0 \mathrm{~N} 3 \mathrm{R}$ isoform (Vermersch et al., 1996). The primary expression of the smaller protein could suggest mis-splicing of the Tau transcripts in DM.

Interestingly, NFTs have also recently been reported in sympathetic ganglions, suggesting a potential association with the peripheral neuropathy observed in some DM1 patients (Kuru et al., 2013; Peric et al., 2013b).

\section{Other histological features}

LBs, which are primarily composed of $\alpha$-synuclein, are characteristic of DLB and Parkinson's disease (PD) but have also been observed in mixed $\mathrm{AD} / \mathrm{LB}$ dementia (Rosenblum and Ghatak, 1979; Gibb et al., 1989; Bose et al., 2008; Echavarri et al., 2012). Interestingly, LBs have also been reported in DM brains in some patients (Itoh et al., 2010), suggesting a possible mixed pathology in these cases.

Analysis employing an anti-ubiquitin antibody revealed Marinesco bodies (MB) in the substantia nigra, which are rarely observed in DM1 patients but numerous in DM2 patients (Maurage et al., 2005). Although MBs have been detected in aging persons, the frequency of these inclusions increases in several diseases, such as DM.

Recently, a new histological feature has been reported in the hippocampal neurons of DM patients (Yamazaki et al., 2011; Nakamori et al., 2012). Granulovacuolar degeneration (GVD) is characterized by the presence of double membrane-bound cytoplasmic vacuoles, which are strongly detected using antibodies directed against late-stage autophagic marker Lamp1. These vacuoles contain an electron-dense granule that contains, at a minimum, endosomal sorting complex required for transport (ESCRT)-III subunits, charged multivesicular body protein $2 \mathrm{~B}$ (CHMP2B), ubiquitin, pSmad2/3, and phospho-TDP-43 (Braak and Braak, 1991; Okamoto et al., 1991; Baig et al., 2009; Yamazaki et al., 2010; Funk et al., 2011). Although detected in the hippocampus in elderly persons, GVD is more frequently present 


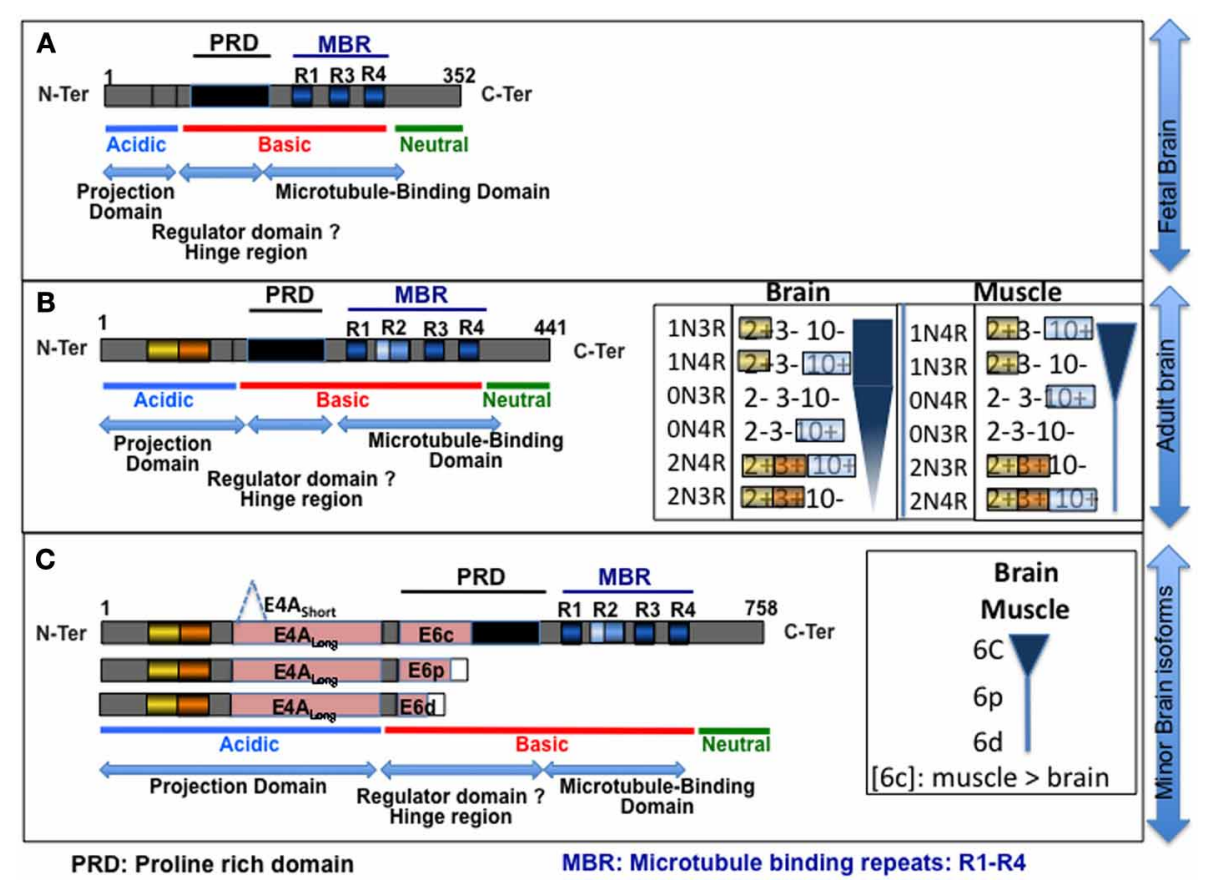

FIGURE 3 | Schematic of the Tau isoforms. (A,B) isoforms primarily expressed in fetal and adult brains, respectively, (C) poorly expressed in brain. The different structural domains are indicated at the bottom of each panel. The inserts in (B) represent the differential expression of Tau isoforms in the adult brain, and the tissue specificity of the splicing is illustrated by comparison with skeletal muscle expression; the width of the diagram corresponds to level of the corresponding isoform [drawn from Mulot et al. (1994), Boutajangout et al. (2004), Andreadis (2005), Trabzuni et al. (2012)]. Exon 4A Short and Long and exons 6c, p, and d correspond to distinct 3 ' sites in exons 4A and 6 (panel C) (Wei and Andreadis, 1998; Souter and Lee, 2010). The inclusion of $6 p$ and $6 \mathrm{~d}$ results in a change in the open reading frame (ORF) and introduces a stop codon, leading to the expression of truncated proteins. Note that the inclusion of exons 3,6, and 4A occurs rarely in the brain. As shown in the insert in (C), exon 6 is primarily detected in muscle compared with the brain (Andreadis, 2005). Exon 4A is primarily expressed in the peripheral nervous system (Couchie et al., 1992; Georgieff et al., 1993), and few data are available concerning this exon. PRD, proline-rich domain; MBR, microtubule-binding repeat: R1-R4. in $\mathrm{AD}$ patients. The GVD load increases with disease severity, NFD, and the decline of episodic memory in AD (Ball, 1977; Ball and Lo, 1977; Ghoshal et al., 2002). GVD has also been reported in other neurodegenerative diseases, such as PiD, PSP, and cortico-basal degeneration (CBD) (Yamazaki et al., 2011).

\section{DM1 AND TAU MIS-SPLICING EVIDENCE FOR TAU MIS-SPLICING}

Tau mis-splicing was first suggested by an abnormal pattern of pathological Tau proteins in the brain tissue of DM1 patients compared with the prototypical quadruplet of pathological tau proteins in the brains of AD patients (Vermersch et al., 1996). Tau mis-splicing in DM1 has clearly been demonstrated at the RNA and protein levels. Thus, in the DM1 brain, there is an overall reduction of Tau protein isoforms with the sequence encoded by exons 2 and 3 due to a deficit in the alternative splicing of these exons (Sergeant et al., 2001; Leroy et al., 2006a). Thus, an exon 2-specific antiserum reveals NFT staining in AD brains but not DM1 brains (Maurage et al., 2005). In addition to exons 2 and 3 , the mis-splicing of Tau has also been reported for exon 10, although this inclusion defect occurs to a lesser extent compared with exon 2 and is not observed in all DM1 brains (Jiang et al., 2004; Dhaenens et al., 2011). We also reported the defective splicing of the minor Tau exon 6 brain cassette (Wei and Andreadis,
1998; Leroy et al., 2006a). Exon 6 is included in the mature mRNA through one of three potential $3^{\prime}$ splice sites, leading to the insertion of the $6 \mathrm{c}, 6 \mathrm{p}$, or $6 \mathrm{~d}$ forms (Figure 2; Andreadis, 2005). A decrease in exon $6 \mathrm{c}$ and an increase in $6 \mathrm{~d}$ have been observed in DM1 brains (Leroy et al., 2006a). Although primarily expressed in the brain, Tau is also expressed in various tissues, and the alternative splicing of this protein is tissue specific. Interestingly, the alteration of Tau alternative splicing in DM1 also seems to be tissue specific, as mis-splicing of exon 2 is observed in both brain and skeletal muscle, whereas mis-splicing of exon 6 (decrease in exon $6 \mathrm{c}$ and increase in $6 \mathrm{~d}$ ) is only observed in the brain (Leroy et al., 2006a).

\section{MECHANISMS}

Two protein families, CELF and MBNL, have been implicated in the mis-regulation of the alternative splicing of muscle and heart transcripts in DM1, including cTNNT2, IR, and ClC-1 (Philips et al., 1998; Ladd et al., 2001; Savkur et al., 2001; Charlet-B et al., 2002; Kanadia et al., 2003; Ho et al., 2004; Kino et al., 2009). In these tissues, CELF1 and MBNL1 are antagonistic regulators of many splicing events altered in DM1, and these events are oppositely regulated during development: CELF1 expression decreases whereas MBNL1 increases during heart development in mice (Kalsotra et al., 2008). Thus, the sequestration of MBNL1 by 
mutated RNAs and the steady-state level of CELF1 in DM1 tissues reproduces the fetal level of these factors, leading to a fetal-type pattern of splicing [recently reviewed in Lee and Cooper (2009), Mastroyiannopoulos et al. (2010), Klein et al. (2011)].

Studies aiming to understand the pathogenic mechanisms involved in mis-splicing events in the brain are less numerous than those concerning mis-splicing in skeletal muscle and the heart. Only Tau is currently being studied. The eventual role of CELF and MBNL proteins in Tau mis-splicing has been investigated for exons 2, 6, and 10, as described below. No data are available concerning the dysregulation of Tau exon 3 splicing. This cassette is rarely included in adult brain Tau transcripts, and few data are available concerning the normal splicing regulation of this exon. However, studies have shown that the inclusion of exon 3 is dependent on the insertion of exon 2 and a weak branch point/poly Y region (Wei and Andreadis, 1998; Arikan et al., 2002; Andreadis, 2005; Trabzuni et al., 2012).

\section{CELF family involvement}

CELF1 (CUG-BP1) was the first CELF protein to be associated with mis-splicing events in the muscle and heart of DM1 patients [reviewed in Cho and Tapscott (2007)]. CELF1 is inefficient in the splicing of Tau exons 2, 6, and 10 (Leroy et al., 2006b; Dhaenens et al., 2011). However, CELF2 (ETR-3) acts as a silencer for both exons 2 and 10 but is inefficient in silencing exon 6 (Leroy et al., 2006a,b; Dhaenens et al., 2011). The role of CELF4 is more ambiguous because this protein inhibits exon 2 inclusion, favors the inclusion of exon 10, and, similar to CELF2, inefficiently modifies exon 6 splicing (Leroy et al., 2006a,b; Dhaenens et al., 2011). CELF5 and CELF6 are the only two CELF members that modify exon 6 splicing and reproduce its DM1 splicing pattern when over-expressed via cell transfection (Leroy et al., 2006a). Notably, neither of these proteins is expressed in muscle; whereas CELF6 is expressed in a subset of tissues, such as brain, kidney, and testis, CELF5 is principally expressed in the brain (Ladd et al., 2001, 2004). This expression pattern could explain why Tau exon 6 mis-splicing is brain specific and suggests that CELF 5 and 6 might play a key role in this specific mis-splicing (Leroy et al., 2006b). These results confirm the complexity and independent regulation of Tau exon splicing in terms of expression profile and regulation, consistent with Andreadis's results (2005). The different levels of splicing alterations for each exon in DM1 might reflect this complexity. Several members of the CELF family could contribute to the global mis-splicing pattern of Tau in the same tissue, but each protein might play a specific role for a given Tau exon. Furthermore, the inefficient regulation of Tau splicing by CELF1 suggests that the Tau exon 2 mis-splicing reported in muscle does not result from an increase in CELF1 activity, similar to other DM1-regulated transcripts, such as Bin-1 (Fugier et al., 2011). Rather, Tau exon 2 mis-splicing might result from the activity of other CELF members, such as CELF2 (Leroy et al., 2006b). An increase in CELF2 activity has been reported in an inducible heart-specific DM1 mouse model (Wang et al., 2007). Similar to the brain, CELF factors other than CELF1 and CELF2 may participate in Tau splicing regulation in muscle; this mechanism has been proposed for other deregulated transcripts in DM. Indeed, Kino et al. reported that CELF 3, 4, 5, and 6 but not CELF1 and CELF2 regulate ClC-1 splicing (Kino et al., 2009).

The different roles of the CELF factors for different Tau exons could explain, at least in part, why the relative exclusion of the main mis-spliced Tau exons in DM, exon 2 and exon 10, differs. Indeed, the exclusion of exon 2 is more important than that of exon 10, and an increase in exon 10 exclusion was not observed in all DM1 brains, in contrast to exon 2 (Jiang et al., 2004; Dhaenens et al., 2011). The CUG expansion length and Tau polymorphism do not play a role in exon 10 mis-splicing susceptibility (Dhaenens et al., 2011). By contrast, variations in exon 10 splicing might be associated with CELF protein expression in the brain. Indeed, CUG-BP1 and CELF2 protein expression varies greatly in DM1 brains: both increased and decreased expression has been observed compared with controls. By contrast, the expression of CELF4 was stable and similar to that of the control (Dhaenens et al., 2011). Interestingly, the brains with greater CELF1 and 2 levels also exhibit variations in exon 10 splicing. Although these observations are correlative, these results suggest the stabilization and activation of at least some of the CELF proteins in the brain, perhaps through a phosphorylation mechanism as described for CELF1 in muscles (Kuyumcu-Martinez et al., 2007, Dhaenes and Sergeant unpublished result].

Moreover, the differing actions of CELF factors on different Tau exons support our hypothesis that Tau exons are independently regulated and further suggest that the splicing misregulations observed during DM1 do not reflect a unique mechanism, consistent with the hypothesis of Jiang et al. (2004) concerning APP, Tau, and NMDAR mis-splicing.

\section{MBNL family involvement}

Interestingly, by favoring fetal-type splicing events, the DM1 mutation favors the expression of long fetal MBNL1 isoforms in DM1 brains, as observed in DM1 muscles (Lin et al., 2006; Dhaenens et al., 2008). Notably, this change is compatible with an increase in MBNL1 nuclear localization and then potentially in its depletion through sequestration in foci (Tran et al., 2011). Mimicking the MBNL1 sequestration in foci, the silencing of MBNL1 expression in cellular models results in the loss of Tau exon 2 insertion, similar to that observed in DM1 brain splicing (Dhaenens et al., 2008, 2011). Surprisingly, Tau splicing remains unchanged in the brains of MBNL1 KO mice, a model that reproduces some of the muscle abnormalities, the cataracts, and the mis-splicing of some RNA transcripts, such as TNNT2 and TNNT3, observed in DM1 (Kanadia et al., 2003; Suenaga et al., 2012). In contrast to the MBNL1 KO model, the preferential exclusion of Tau exons 2 and 3 is observed in mice lacking MBNL2, a new model that reproduces the brain but not muscle pathology of DM1 (Charizanis et al., 2012). Exon 10 splicing has not been reported in this MBNL2 KO model. Similar to exon 2, MBNL1 silencing also favors exon 6 exclusion in a manner similar to that observed in the DM1 brain, whereas exon 10 splicing is not modified (Leroy et al., 2006a; Dhaenens et al., 2011). This last result is consistent with the differential regulation of exon 2 and 10 splicing, as reported in CELF regulation. However, the results of a recent study concerning the impact of MBNL1 silencing efficiency on the number and severity of splicing alterations 
in a myoblast model suggest a need to re-examine the influence of MBNL1 activity on Tau exon 10 regulation in a more robust inducible system using stable cell lines (Jog et al., 2012).

\section{EFFECTS OF DM1 MIS-SPLICING ON TAU FUNCTION}

Splicing is a discrete cellular mechanism to modulate protein function. Thus, mis-splicing leads to modifications of protein activity. Most of the tauopathies for which an alteration of Tau alternative splicing has been reported are characterized by an alteration of exon 10 inclusion/exclusion. Thus, three isoforms are expressed according to the insertion or exclusion of exons 2 and 3 (Sergeant et al., 2008). DM is the only tauopathy characterized by the extensive alteration of Tau splicing involving exons $2,3,6$, and 10 , resulting in the primary expression of only one isoform. Although the role of each exon-coded sequence is not well-defined, we will discuss the potential consequences of DM mis-splicing on Tau function.

\section{Tau protein structure}

Tau is a "natively unfolded" protein (Schweers et al., 1994; Jeganathan et al., 2008), but short sequences (maximum of 10 residues) transiently adopt secondary structures, facilitating transient functions such as protein-protein interactions (Mukrasch et al., 2009). In solution, Tau adopts a "paperclip" structure resulting from interactions between the $\mathrm{N}$ and $\mathrm{C}$ termini of the Tau and microtubule-binding domains (MBDs). This structure is independent of the presence/absence of exons 2, 3, and 10 (Jeganathan et al., 2008).

The Tau protein has been divided into various regions based on chemical (basic, acidic, neutral), biochemical (proline-rich domain (PRD), hinge region, repeats), or functional features (projection domain, microtubule-binding region). As shown in Figure 3, the insertion of alternatively spliced exons extends the different domains in which these sequences are inserted: exons 2, 3 , and $4 \mathrm{~A}$ lengthen the acidic region and, consequently, the projection domain, whereas exons $6 \mathrm{c}$ and 10 length the basic region, PRD, and MBR. None of the additional alternative sequences disrupt the properties of the domain in which they are inserted.

\section{Effects of mis-splicing on Tau binding to membranes and its secretion}

The $\mathrm{N}$ terminus of Tau (amino acids 2-18) has been implicated in its binding to the plasma membrane. Although the exon 2encoded sequence is located proximal to this site, there are no reports on the influence of this sequence and its phosphorylation on Tau binding to membranes. However, an effect of the exon 2encoded sequence on the secretion of $\mathrm{N}$-terminal fragments has been reported (Kim et al., 2010).

\section{Effects of mis-splicing on tau aggregation}

The microtubule-binding repeats (MBRs) are essential for Tau fibrillization, whereas the flanking regions are inhibitory (Wille et al., 1992; Alonso et al., 2001). Two short peptides encoded by exons 11 (PHF6) and 10 (PHF6*) have been identified as major factors in the aggregation of Tau (Von Bergen et al., 2000, 2001; Li and Lee, 2006). The first motif, encoded by exon 11, is sufficient to promote aggregation, whereas the second motif, encoded by exon 10, facilitates aggregation. Thus, a loss of Tau isoforms with 4 MBRs would prevent the aggregation of this protein.

The role of the exon 2 -encoded sequence in Tau aggregation has recently been described. The exon 2 -encoded sequence promotes the fibrillar extension of Tau filaments but does not promote the nucleation of Tau aggregates (Zhong et al., 2012). By contrast, the inclusion of the Tau exon 3-encoded sequence diminishes the fibrillar extension, consistent with a potential protective effect of exon 3, as suggested by its higher inclusion in association with the $\mathrm{H} 2$ haplotype, a protective haplotype with respect to tauopathy development, compared with $\mathrm{H} 1$ haplotype (Trabzuni et al., 2012). However, Tau hyperphosphorylation might interfere with the aggregation of Tau isoforms. Indeed, in a cellular model, Tau pseudo-phosphorylation at sites common to the different Tau isoforms inhibits the aggregation of all $3 \mathrm{R}$ isoforms but has little effect on the aggregation of $2 \mathrm{~N} 4 \mathrm{R}$ $(2+3+10+$ isoform $)$ and $1 \mathrm{~N} 4 \mathrm{R}(2+10+$ isoform $)$, and enhances the aggregation of $0 \mathrm{~N} 4 \mathrm{R}$ (10+ isoform) (Combs et al., 2011).

Altogether, these observations suggest that the decrease in the inclusion of exons 2, 3, and 10 in DM1 might be protective with respect to Tau aggregation in DM1. However, note that the toxicity of aggregated tau is yet a matter of debate. A possible role of these aggregates in neuroprotection as well as a toxicity of soluble forms of Tau have been reported and recently reviewed in Cowan and Mudher (2013).

\section{Effects of mis-splicing on protein-protein interactions}

Tau carries many ionic charges and contains a PRD, which enable it to potentially interact with many protein partners; however, these interactions are transient and difficult to detect.

Interaction studies have primarily been performed using the longest isoform of Tau (2N4R) first identified in the brain or some region of this isoform [for a review, see Mandelkow and Mandelkow (2012)]. Only interactions with sequences encoded by exons 2, 3, and 10 might be reduced or promoted in DM1 compared to control. As described below, while Tau protein interactions with microtubules are dependent on the insertion or omission of the sequence encoded by exon 10, these interactions might also depend on the phosphorylation state of the protein, particularly in the MBR and neighboring regions [reviewed in Sergeant et al. (2005)]. HSP70 binding to Tau affects microtubule polymerization and efficiently inhibits Tau aggregation (Dou et al., 2003; Sahara et al., 2007; Voss et al., 2012). These effects are isoform dependent. The anti-aggregative effect of HSP70 is higher for $3 \mathrm{R}$ isoforms than $4 \mathrm{R}$ isoforms. Thus, these results are also in agreement with the moderate development of the tauopathy in the DM1 brain.

Exon $6 \mathrm{c}$ is the most frequent form of exon 6 inclusion, but no data concerning its possible interactions with other partners are available. Exon $6 \mathrm{c}$ inclusion lengthens the PRD, and the encoded sequence is rich in putative sites of phosphorylation, features that modulate protein functions and interactions. In addition to the 85 putative sites present on the $2 \mathrm{~N} 4 \mathrm{R}$ isoform, the exon 6 c-encoded insert ( 66 amino acids) introduces 22 new putative sites of phosphorylation ( $21 \mathrm{Ser} / \mathrm{Thr}$ and $1 \mathrm{Tyr}$, i.e., $1 / 3$ residues), four of which could be proline-dependent. However, the impact of the exon $6 c$-encoded sequence on Tau phosphorylation is yet 
unknown. Although Tau containing exon 6c-encoded sequence binds microtubules, it might serve as an inhibitor of axon elongation, particularly when the Tau isoforms also contain exon 2- and exon 3-encoded sequences (Luo et al., 2004a,b).

\section{Effects of mis-splicing on microtubule stabilization and axonal transport}

The MBR comprises three (3R) or four (4R) tubulin-binding repeats depending on the insertion or omission of the sequence encoded by exon 10. The insertion of a fourth microtubulebinding domain (the second one in the primary structure of the protein) enhances microtubule binding by Tau by 40 -fold and, consequently, also enhances the stability of the microtubules (Goode and Feinstein, 1994). Consequently, 4R-Tau is a potent inhibitor of MT shortening, in contrast to the 3R-Tau isoforms (Bunker et al., 2004). In the human adult brain, the ratio between $3 \mathrm{R}$ and $4 \mathrm{R}$ is $1: 1$, and both the $3 \mathrm{R}$ and $4 \mathrm{R}$ proteins are detected throughout the brain (Mulot et al., 1994; Boutajangout et al., 2004; Trabzuni et al., 2012). Thus, the loss of the Tau 4R protein observed in DM1 might result in a loss of microtubule stabilization and an increase in neuronal plasticity.

The Tau 3R/4R balance could also affect other Tau properties. Indeed, Tau affects organelle transport by reducing the attachment frequency of motors to microtubules (Sato-Harada et al., 1996; Trinczek et al., 1999; Seitz et al., 2002; Mandelkow et al., 2004) or differentially regulating kinesin- and dynein-based transport (Dixit et al., 2008; Vershinin et al., 2008). According to Dixit et al. (2008), Tau interferes with anterograde transport by inducing kinesin detachment. However, by reversing the direction of dynactin-dynein motor proteins, Tau also interferes, to a lesser extent, with retrograde transport. The perturbations of kinesin and dynein-dynactin migration are both dependent on the Tau isoform; the shortest Tau isoform $(0 \mathrm{~N} 3 \mathrm{R})$ is a more potent inhibitor than the longest isoform (2N4R) (Dixit et al., 2008). Thus, the overexpression of the fetal form (0N3R) and the disappearance of the adult forms might lead to an increased perturbation of axonal transport in the DM1 brain compared to other tauopathies, such as $\mathrm{AD}$, as well as increased neuronal plasticity. Interestingly, both the $\mathrm{N}$ - and C-halves of Tau interfere with kinesin-mediated axonal transport. First, Tau 3R has a more significant effect than Tau 4R on both kinesin and dynein binding and progression along stabilized microtubules (Vershinin et al., 2007, 2008; Stoothoff et al., 2009), while Tau 4R but not Tau 3R enhances the velocity of kinesin (McVicker et al., 2011). Second, the $\mathrm{N}$ terminus inhibits fast anterograde transport (FAT) by activating the PP1-GSK3 pathway due to the exposure of the phosphatase-activating domain (PAD) in aggregated Tau (LaPointe et al., 2009; Kanaan et al., 2011). However, the phosphorylation of Tau Y18, an AD-specific phosphorylation site and Fyn substrate, prevents the effect of Tau on FAT (Kanaan et al., 2012). Note that sequences encoded by exons 2 and 3 lengthen the Tau projection domain, resulting in an increase in the space between microtubules (Kanai et al., 1992). Thus, these sequences might reinforce the effects of Tyr18 phosphorylation on axonal transport. Indeed, the space between microtubules was recently shown to be a potential determinant in mitochondrial transport (Shahpasand et al., 2012).
Axonal transport also depends on Tau exon 6 splicing. The 6pand $6 \mathrm{~d}$-containing forms are sufficient to perturb FAT because these short isoforms cannot adopt the "paperclip conformation" in the absence of the C-terminus, leading to the spontaneous exposure of the PAD domain (LaPointe et al., 2009; Kanaan et al., 2011). Thus, although exon 6 is a minor cassette in DM1, the increase in $6 \mathrm{~d}$ levels could contribute, even weakly, to the disruption of axonal transport in DM1 patients.

In conclusion, by favoring the fetal Tau isoform $(0 \mathrm{~N} 3 \mathrm{R})$ and increasing the minor $6 \mathrm{~d}$ forms, changes in Tau alternative splicing might result in a variation of microtubule bundle organization and axonal transport in the DM1 brain and an enhanced secretion and diminished aggregation of Tau.

\section{COMMON FEATURES OF DM AND OTHER TAUOPATHIES}

The term tauopathy merges nearly 30 diseases characterized by Tau aggregation and neurodegeneration due to various factors, such as genetic (mutations or polymorphisms/haplotypes of different genes), environmental (trauma), and molecular factors (with or without amyloid cascade contributions) [reviewed in Sergeant et al. (2005)]. In DM, the expansion of oligonucleotide repeats (CTG/CCTG) leads to tauopathy. Thus, there are interconnections of the different pathways that are initiated by distinct factors and lead to both tau aggregation and neurodegeneration. What are the common determinants and crucial steps of these different diseases that contribute to tauopathy development?

\section{TAU MIS-SPLICING}

Tau mis-splicing has been implicated in tauopathy development since the discovery that Tau mutations in intronic sequences resulted in both splicing deregulation and tauopathy in FTDP17 cases. Indeed, Tau mis-splicing has been identified in various tauopathies, such as FTDP-17, PSP, CBD, argyrophilic grain disease, $\mathrm{DM}$, and, to a lesser extent, $\mathrm{AD}$ and Down syndrome (Sergeant et al., 2005). Notably, the mechanisms of mis-splicing might differ according to the disease. In FTDP-17, mis-splicing is due to cis-factors, i.e., Tau mutations, at sites involved in splicing factor binding. In DM, mis-splicing is due to a disruption in the ratio of some splicing regulator trans-factors, particularly those belonging to the CELF and MBNL families. In other cases, such as PSP and CBD, the mechanisms differ according to familial or sporadic forms of the disease. In familial cases, Tau $4 \mathrm{R}$ over-expression results from Tau mutations in the binding site of regulator factors. In sporadic forms, Tau $4 \mathrm{R}$ over-expression is dependent on the Tau haplotype. Indeed, the H1 MAPT haplotype has been consistently associated with PSP (Rademakers et al., 2005). Down-regulation of miR-132 in the brains of PSP patients was recently reported. Furthermore, silencing of this miR leads to an increase in the ratio of the Tau $4 \mathrm{R} / 3 \mathrm{R}$ isoforms (Smith et al., 2011). Thus, in some tauopathies, mis-splicing could be associated with variations in $\mathrm{miR}$ expression.

Taken together, these data indicate that dysregulation of the balance between the different Tau isoforms is a sufficient factor to trigger tauopathy. Although an increase in Tau 4R levels is the most frequent dysregulation observed in FTDP-17, PSP, and $\mathrm{CBD}$, the overexpression of $3 \mathrm{R}$ isoforms is associated with tauopathies such as rare FTDP-17 cases and PiD. In these different 
pathologies, no splicing error in exons 2 or 3 has been reported. The DMs are the first pathologies in which global indirect Tau mis-splicing, i.e., errors in the splicing of exons 2, 3, 6, and 10, have been observed (Sergeant et al., 2001, 2008; Jiang et al., 2004; Leroy et al., 2006b).

Conflicting data concerning $\mathrm{AD}$ have been reported. Missplicing is difficult to demonstrate in whole tissues because only some neurons, particularly cholinergic neurons, are degenerating. The number of degenerating neurons is a function of the area and stage of the pathology. Thus, some studies have not detected changes in splicing during $\mathrm{AD}$, while others have reported an increase in exon 10 inclusion, although this increase is lower than that observed for other tauopathies (Baker et al., 2000; Boutajangout et al., 2004; Connell et al., 2005; Glatz et al., 2006; Ingelsson et al., 2006; Conrad et al., 2007; Abraham et al., 2009). Only one study reported an alteration in exon 2 splicing, which involved a decrease in exon 2 inclusion. Interestingly, an increase in exon 3 inclusion has been reported in cells and subjects with the H2 haplotype (Conrad et al., 2007; Caffrey et al., 2008; Wegiel et al., 2011; Trabzuni et al., 2012), which is protective compared with H1. A study of Down syndrome patients developing AD with aging suggests an increase in exon 10 exclusion (Wegiel et al., 2011).

\section{DIABETES AND METABOLIC SYNDROME}

Another common feature of DM1 and some tauopathies involves insulin metabolism and associated diseases. Although the importance of insulin resistance in DM remains controversial (Perseghin et al., 2004), DM1 patients exhibit peripheral insulin resistance with glucose intolerance, hyperinsulinemia, and an increased risk of developing type II diabetes (T2DM) (5-17\% of patients) (Moxley et al., 1984; Savkur et al., 2001; Rakocevic Stojanovic et al., 2010; Kaminsky et al., 2011). This peripheral insulin resistance might be due to the IR splicing alterations observed during DM (Savkur et al., 2001, 2004). However, the relationship between IR splicing, insulin resistance, and T2DM is unclear. Although the overexpression of IR A (i.e., the IR isoform without the exon 11-encoded sequence) has been reported in one T2DM case with extreme insulin resistance and hyperinsulinemia (Norgren et al., 1994), a decrease in the IR A form has been more frequently reported in T2DM (Mosthaf et al., 1991; Sesti et al., 1991; Kellerer et al., 1993; Norgren et al., 1993). However, this alteration has not been observed by other groups (Benecke et al., 1992; Anderson et al., 1993; Hansen et al., 1993). By contrast, an increase in IR A expression similar to that observed in DM1 has been evidenced in obese and early-stage diabetic rhesus monkeys, supporting the hypothesis of a relationship between IR splicing and diabetes (Huang et al., 1994, 1996).

Interestingly, metabolic syndromes, including T2DM, are also a significant risk factor for AD [reviewed in Frisardi et al. (2010), Bosco et al. (2011)]. Hyperglycemia leads to an excessive peripheral utilization of insulin, resulting in reduced insulin transport to the brain. Brain insulin plays a role in neuron survival, learning memory, synaptic plasticity, and neuronal energy homeostasis [reviewed in Belfiore et al. (2009)]. Intranasal administration of insulin has potential beneficial cognitive effects, confirming the possible deleterious impact of insulin in AD (Reger et al., 2008;
Shemesh et al., 2012). Insulin could interfere with pathological processes at various stages. First, insulin resistance has been suggested to be involved in cognitive impairment (Bruehl et al., 2010). Second, insulin might accelerate AD-related pathology through its effects on amyloid beta $(\mathrm{A} \beta)$ metabolism and Tau phosphorylation [reviewed in Bosco et al. (2011)]. Interestingly, intranasal insulin partially corrects Tau hyperphosphorylation in diabetic rats (Yang et al., 2013). Third, the increased expression of three-repeat isoforms of Tau could contribute to the Tau pathology in a rat model of chronic type 2 diabetes (Jung et al., 2011). Notably, increases in both Tau phosphorylation and Tau 3R levels have also been observed in DM1 patients. Furthermore, in the absence of peripheral insulin resistance but up-regulation of hippocampal insulin signaling, early and progressive obesity potentiated spatial learning deficits and hippocampal Tau pathology at a later stage in transgenic THY-Tau22 mice (Leboucher et al., 2013). Interestingly, Tau phosphorylation and/or $A \beta$ oligomerization/aggregation have been observed in several diabetic mouse or rabbit models, confirming a possible relationship between AD disease and diabetes (Li et al., 2007; Planel et al., 2007; Jolivalt et al., 2010; Bitel et al., 2012; Papon et al., 2013).

\section{COMMON MOLECULAR ACTORS IN DM AND AD}

Various molecular actors are common between DM and tauopathies such as $\mathrm{AD}$ and are therefore of particular interest for understanding pathological processes. The contribution of these different actors to Tau aggregation and neurodegeneration has not been well-elucidated. Nevertheless, the deregulation of the function of these proteins could be a metabolic event contributing to the common pathological aspects of these diseases, i.e., the development of a tauopathy. Thus, we will discuss these common actors and how they are involved in either DM or tauopathy.

\section{Bin-1}

Tau is not the only transcript targeted by the DM1 mutation that is ubiquitously expressed, but the DM1 mis-splicing is often reported for only one tissue. For Bin-1, the preferential exclusion of muscle-specific exon 11 has been reported in DM1 muscle compared with healthy persons and has been associated with T tubule alterations and muscle weakness (Fugier et al., 2011). Other exons of Bin-1 such as exons 7 and 13-16, are brain specific, but their eventual mis-splicing has not been investigated, and therefore the contributions of these entities cannot be ruledout. Although Bin 1 mis-splicing has not been established in the DM brain, Bin1 is a recently identified genetic marker for predisposition to the most frequent tauopathy, AD (Seshadri et al., 2010; Carrasquillo et al., 2011; Lambert et al., 2011; Logue et al., 2011; Wijsman et al., 2011). A particular variant, located $28 \mathrm{~kb}$ upstream of Bin-1, has been associated with risk for AD, particularly the Tau load in the brains of AD patients. This SNP results in the increased expression of Bin-1. Bin-1 is highly expressed in neuronal tissue, and its role in neurons must be accurately determined. Bin-1 is suspected to interfere with synaptic function and cell membrane processes and might be associated with receptordependent signaling pathways (Leprince et al., 1997; Morgan, 2011). Interestingly, Bin-1 interacts with Tau proteins (Chapuis et al., 2013). 


\section{APP}

Jiang et al. (2004) reported a default in APP splicing in DM1 patients, characterized by a decrease in exon 7 inclusion. The sequences encoding exons 7 and 8 are specifically excluded from the neuronal APP form (APP695) but are included in astrocytic APP isoforms (APP 751, APP770). Interestingly, a change in the APP splicing pattern has also been observed in the brains of AD patients. In contrast to the DM brain, the modified splicing corresponds to an increase in exon 7 inclusion in the $\mathrm{AD}$ brain (Johnson et al., 1989; Tanaka et al., 1989). However, changes in APP splicing are somewhat difficult to interpret because APP is expressed in both neurons and astrocytes. An increase in exons 7 and 8 might either correspond to the mis-splicing of APP transcripts in neurons or result from neuronal loss or astrocytosis, both events observed in AD (Donev et al., 2009; Rodriguez et al., 2009). In DM1, a decrease in exon 7 inclusion might be indicative of mis-splicing in astrocytes. The functional consequences of changes in APP splicing in astrocytes remain ill-defined.

In addition to mis-splicing, defects in APP metabolism have been strongly associated with the development of some tauopathies, particularly AD [recently reviewed in Huang and Mucke (2012)]. Indeed, APP proteolysis is modified during AD, favoring the production of $A \beta 1-42$ or $A \beta N-42$ peptides, which aggregate in the extracellular space. $A \beta 1-42$ dosage is one of the three biological markers indicative of an $\mathrm{AD}$ diagnosis: $\mathrm{A} \beta 1-42$ is decreased in the cerebrospinal fluid (CSF) of AD patients, whereas total Tau and phosphorylated Tau levels are increased (Blennow and Hampel, 2003; Herukka et al., 2005; Bombois et al., 2013). Decreased $A \beta 1-42$ levels in the CSF have also been observed in various tauopathies and other diseases, such as Creutzfeld-Jacob disease and Multiple System Atrophy (Van Everbroeck et al., 1999; Otto et al., 2000; Sjogren et al., 2002; Noguchi et al., 2005). Interestingly, the analysis of CSF in DM patients also revealed a significant decrease in A $\beta 1-42$ compared with matched controls (Winblad et al., 2008; Peric et al., 2013a). While a decrease in the $\mathrm{A} \beta 1-42$ level in the CSF of AD patients is associated with the presence of the cerebral aggregation of this peptide, this is not the case for other tauopathies, particularly DM (Kiuchi et al., 1991; Figure 1).

\section{NMDAR}

In the DM1 brain, defective splicing of NMDA-R1 is observed, which, in conjunction with altered Tau splicing, suggests defective neuronal plasticity. This splicing change corresponds to an increase in exon 5 inclusion in NMDAR1 transcripts (Jiang et al., 2004) and could result in the functional modification of the protein, although this possibility remains to be determined. Nmethyl-D-aspartate receptors (NMDAR) are multimeric ligandgated ion channels comprising at least one member of the NMDA receptor 1 subunit (NMDAR1) family and one of four different subunits of the NR2 family (NMDAR2 A-D). These receptors play a role in neuronal plasticity, but over-activation of these receptors results in excitotoxic damage (Chandler et al., 1998; Jaekel et al., 2006). The NMDAR1 family comprises eight alternatively spliced variants generated through the alternative splicing of exons 5, 21, and 22 (Laurie and Seeburg, 1994; Zukin and Bennett, 1995). The splicing pattern varies during development, across brain regions, and among subtypes of neurons. The presence of exon 5-encoded sequences determines the sensitivity of NMDAR to protons and polyamines and accelerates receptor deactivation after brief agonist exposure (Traynelis et al., 1995, 1998; Rumbaugh et al., 2000).

Interestingly, a pivotal role for NMDAR-mediated toxicity has been suggested in $\mathrm{AD}$ and tauopathies. Indeed, an overactivation of N-methyl-D-aspartate glutamate (NMDA) receptors, which permits excessive $\mathrm{Ca}^{2+}$ influx through associated ion channels, would induce damage and neuronal cell death. NMDAR function can also be modulated through the metabolite products of APP and Tau, proteins essential to AD development. Indeed, the over-expression of human Tau and its N-terminal fragments in primary neuronal cultures leads to $\mathrm{N}$-methyl-D-aspartate receptor (NMDAR)-mediated cell death. As a feedback loop, NMDAR stimulation causes calpain activation, followed by Tau protein proteolysis, resulting in highly toxic $\mathrm{N}$-terminal peptides, such as the 17-kDa peptide (Amadoro et al., 2006). This feedback might be associated, at least in part, with the presence of Tau in the dendritic spines and the axonal localization of this protein. Moreover, naturally secreted $A \beta$ dimers and trimers but not monomers induce the progressive loss of hippocampal synapses, mediated through the activity of NMDARs (Shankar et al., 2007). Thus, NMDAR antagonists, such as Memantine, a drug that blocks ion channel formation mediated through NMDARs, are presently used in AD treatment [reviewed in Schmitt (2005) and Dominguez et al. (2011)]. Memantine might also inhibit Tau and APP protein translation, mediated through the internal ribosome entry site (IRES) of their transcripts. Thus, Memantine inhibits the neuronal expression of Tau and APP proteins, two essential actors in AD (Wu and Chen, 2009). Memantine has also been reported to block the increase in $\mathrm{Ca}^{2+}$ flux and oxidative stress induced through soluble $\mathrm{A} \beta$ oligomers (De Felice et al., 2007).

\section{CELF2}

CELF proteins, particularly CELF1 and CELF2, play an important role in DM1 mis-splicing. In the brain, CELF2 regulates the splicing of NMDAR exon 5 and Tau exons 2 and 3, thus acting as a silencer, whereas CELF1 is inefficient (Zhang et al., 2002; Leroy et al., 2006a; Dhaenens et al., 2011). Curiously, the genome-wide association of familial late-onset AD with CUGBP2 SNPs has been reported in patients with ApoE e4/e4 genotypes, i.e., patients with high risk of developing late-onset AD (Wijsman et al., 2011). However, the relationship between CELF2 SNPs and AD has not been elucidated.

\section{BEYOND TAUOPATHY \\ A TOXIC GAIN-OF-FUNCTION OF RNA}

As detailed in the two preceding sections, Tau mis-splicing induced by CTG mutation has been suggested to be sufficient to induce tauopathy. But is tauopathy sufficient to explain all the brain defects in DM1? Animal models could be useful to answer this question. Two animal models have been described to develop brain pathology: the MBNL2-KO mouse model and transgenic CUG SXXL mice (Gomes-Pereira et al., 2007; Charizanis et al., 2012; Huguet et al., 2012). To date, no data concerning an eventual tauopathy in these models have been reported. 
Interestingly, Tau pathology has also been observed in some mixed amyotrophic lateral sclerosis (ALS)/FTD cases bearing GGGGCC expansions in C9ORF72, suggesting that some patients with nucleotide repeat expansions could develop a mixed pathology (Bieniek et al., 2013; King et al., 2013). Moreover, this observation also suggests a close relationship between oligonucleotide expansion, neuropathology, and tauopathy, and in the absence of mis-splicing, tauopathy could be a secondary consequence of neuropathy associated with oligonucleotide repeat expansion. Thus, it would be interesting to identify tauopathy in other diseases with repeat expansions.

However, other observations argue that some neurological dysfunctions occur independent of tauopathy development. Indeed, it is strange that all expanded repeat mutations, which cause more than 20 diseases, lead to neuropathologies. Why is this type of mutation preferentially associated with this type of disease? The repeat expansions differ with respect to their identity, number, and functional consequences and are harbored by different genes, leading to differential patterns of tissue expression. These pathologies present divergent pathological pathways; in particular, these expansions can either affect protein function or result in a gain of toxic function of the mutated RNA. A gain of toxic function of the mutated RNA was first reported in a study concerning DM1 and subsequently reported for other pathologies, such as HDL2, SCA8, 10, 31, FXTAS, and more recently, FTD, amyotrophic lateral sclerosis (ALS), mixed ALS/FTD cases, and SCA36 [reviewed in La Spada and Taylor (2010), DeJesusHernandez et al. (2011), Renton et al. (2011), Wojciechowska and Krzyzosiak (2011), Garcia-Murias et al. (2012), Ikeda et al. (2012), Simon-Sanchez et al. (2012)]. These pathologies are characterized by a nuclear aggregation of mutated transcripts (called foci) and a change in the alternative splicing of numerous transcripts. The protein trapped by the foci is dependent on the pathologies. Indeed, nuclear foci can sequester MBNL1 proteins in pathologies with CUG, CCUG, or CAG, CGG repeat expansions (Miller et al., 2000; Fardaei et al., 2002; Rudnicki et al., 2007; de Mezer et al., 2011) and hnRNPK in SCA10 (White et al., 2010) and Sam68 in FXTAS (CGG expansion), which also recruit MBNL1 and hnRNPG in foci (Iwahashi et al., 2006; Sellier et al., 2010). Recent reports have suggested that the distinction between diseases with expanded oligonucleotide repeats characterized by a gain of RNA function and those characterized by a gain of protein function is not so obvious [reviewed in Batra et al. (2010)]. SCA8 is the first disease for which bidirectional transcription leading to both RNA and protein dysregulation has been reported (Moseley et al., 2006). Indeed, a newly defined molecular mechanism, "repeat-associated non-ATG initiated translation (RAN translation)," results in the accumulation of SCA8 polyalanine and DM1 polyglutamine in, respectively, SCA8 and DM1 human tissues and mouse models ( $\mathrm{Zu}$ et al., 2011). Nevertheless, the contribution of these proteins to disease pathology has not been elucidated. Similarly, both nuclear foci and polyglutamine protein aggregation have been reported in HDL2, another CTG expansion disease (Holmes et al., 2001; Rudnicki et al., 2007; Wilburn et al., 2011). Other mechanisms, such as haploinsufficiency, anti-sense RNA, and miRNA, have been suggested to interfere with pathology development [recently reviewed in Klein et al. (2011), Sicot et al. (2011); Udd and Krahe (2012)]. Thus, the neurological specificity of these pathologies might be determined by the as-yet undetermined pathological processes that they share.

\section{SPLICEOPATHY AND NEUROLOGICAL DISORDERS}

Alternative splicing is involved in numerous neurological diseases and can be associated with either the disruption of cis-splicing sites or trans-acting factors [reviewed in Mills and Janitz (2012); Feng and Xie (2013)]. In addition to diseases with a gain of toxic RNA function (described above) and tauopathy associated with Tau mis-splicing (see Part III), a relationship between splicing and neuronal dysfunction has been demonstrated for other neurological pathologies, such as spinal muscular atrophy (SMA). SMA is a recessive autosomal disease associated with the dysfunction of the survival of motor neurons protein (SMN), a RNA-binding protein required for the efficient assembly of small nuclear ribonucleoprotein (snRNP) complexes and spliceosomal snRNP biogenesis. This protein has therefore been indirectly implicated in general cellular RNA processing. By modifying the pre-mRNA splicing machinery, mutated SMN might interfere with mRNA biogenesis (Lefebvre et al., 1995; Pellizzoni et al., 2002; Zhang et al., 2008). Moreover, Lotti et al. (Lotti et al., 2012) recently demonstrated that SMN interferes with the U12 splicing mechanism, a minor alternative process to classical splicing, and SMN depletion alters the splicing of 18 exons, particularly in Stamsimon transcripts, resulting in motor neuron degeneration. SMN also binds FMRP, a defective protein in Fragile X mental retardation syndrome that is associated with mRNA transport and translation (Piazzon et al., 2008).

Other neurological pathologies associated with the dysfunction of RNA-binding factors include ALS and FTD, which is induced by mutations in the TDP-43 and FUS genes (Kabashi et al., 2008; Sreedharan et al., 2008; Vance et al., 2009). TDP43 regulates the splicing of several human transcripts, particularly those of SMN, serine/arginine-rich splicing factor 2 (SC35), S6 kinase 1(S6K1), and Aly/REF-like target (SKAR), a component of the exon junction complex (EJC) (Bose et al., 2008; Dreumont et al., 2010; Tollervey et al., 2011; Fiesel et al., 2012). Consistent with its function as an RNA-binding protein, TDP-43 associates with many other RNA-binding proteins, such as hnRNP A2/B1, hnRNP A1, hnRNP C1/C2, hnRNP A3, and FUS (which is involved in splicing processes and whose mutations are responsible for 5\% of FTD) (Yang et al., 1998; Buratti et al., 2005; Freibaum et al., 2010; Ling et al., 2010). Furthermore, the loss of TDP-43 has recently been associated with long pre-mRNA depletion, RNA mis-splicing (Polymenidou et al., 2011; Tollervey et al., 2011), and a potential role for TDP-43 in axonal mRNA regulation and miRNA biogenesis associated with neuronal outgrowth (Fallini et al., 2012; Kawahara and Mieda-Sato, 2012). The role of FUS, the second protein involved in ALS/FTD, as a brain RNA splicing regulator (Rogelj et al., 2012), particularly for Tau and RNA-binding protein splicing (Orozco et al., 2012; Nakaya et al., 2013), has only recently been described. Both FUS and TDP-43 preferentially bind to extra-long introns, likely to protect these regions from incorrect splicing at cryptic sites (Lagier-Tourenne et al., 2012). 


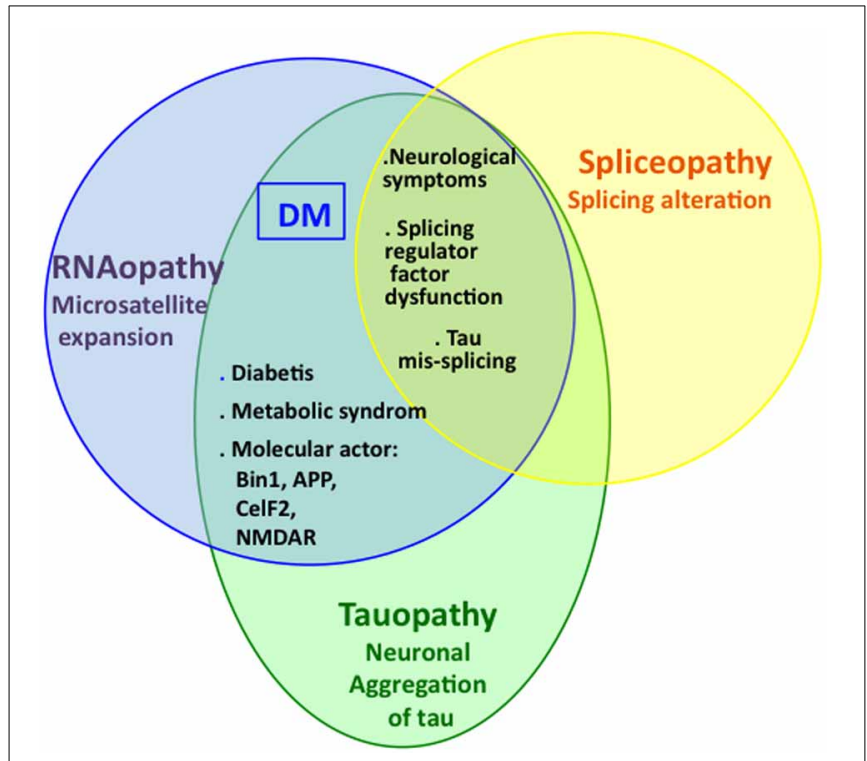

FIGURE 4 | The complex interaction between RNAopathy,

spliceopathy, and tauopathy. DM diseases are the first pathologies for which these interactions have been established.

Although mis-splicing has clearly been demonstrated for various pathologies, including some tauopathies, recent studies have indicated the dysfunction of different splicing regulators in other diseases; however, a clear relationship with a particular splicing event has not been established in these latter diseases [see review Mills and Janitz (2012)]. The hnRNP A1 polymorphism is a genetic factor for some FTLD (Villa et al., 2011), and mutated RBFox1 has been associated with mental retardation, epilepsy, and autism spectrum disorders (Bhalla et al., 2004; Barnby et al., 2005; Martin et al., 2007; Sebat et al., 2007). SRP20, TDP-43, hnRNP-A/B, and CELF2 have been associated with AD (AmadorOrtiz et al., 2007; Uryu et al., 2008; Wijsman et al., 2011; Berson et al., 2012; Wong et al., 2012), and SFPQ has been associated with $\mathrm{AD}$ and PiD (Ke et al., 2012). These observations suggest that the involvement of RNA-binding proteins, particularly splicing regulator factors, largely contributes to the neurodegenerative process. Indeed, these factors can be involved in numerous splicing events, and the modulation of their activity resulting from the modification of the expression and localization of these factors could explain the variations in the alternative splicing of various transcripts detected in neurodegenerative diseases such as AD, Parkinson's disease, and schizophrenia (Twine et al., 2011; Cohen et al., 2012; Soreq et al., 2012; Wu et al., 2012; Wong, 2013) [recently reviewed in Cooper-Knock et al. (2012)]. However, these factors assume other functions, such as RNA export and RNA stabilization. Thus, a role of these factors in pathology through mechanisms other than splicing alterations cannot be excluded.

The deregulation of splicing could also result from snRNP deregulation, as recently suggested for AD. The accumulation of both U1SnRNP and U1-70K, elements essential to the splicing mechanism, has recently been associated with $\mathrm{AD}$ and unspliced RNA accumulation (Bai et al., 2013).
Taken together, these examples indicate that the modification of the splicing factor pool and the deregulation of snRNPs involved in splicing exert a toxic effect in humans; thus, the modification of the splicing pool induced by DM1 mutations might also be associated with neuronal dysfunctions other than tauopathies and Tau splicing alterations.

\section{CONCLUSION}

DM is the first pathology identified as a combination of tauopathy, spliceopathy, and RNAopathy. Indeed, DM1 is the first identified pathology for which the tauopathy has been associated with an expansion of oligonucleotide repeats (Sergeant et al., 2001). It has been hypothesized that this DM-associated tauopathy might result from Tau mis-splicing induced through RNAopathy. This relationship between Tau mis-splicing and tauopathy has previously been reported for some FTD, and particularly for some cases of FTDP-17 with specific Tau mutations. However, Tau mis-splicing is only one among other molecular mechanisms for the induction of tauopathy. Indeed, other tauopathies have been associated with mutations in different genes: APP, PS1, and PS2 (three genes involved in the amyloid cascade in AD); MAPT (Tau gene) (other mutations than those involved in splicing default), or the MAPT haplotype. Thus, various pathological mechanisms lead to tauopathy development, such as Tau mis-splicing in some cases of FTDP-17 and the amyloid cascade in AD, explaining why these pathologies, although clinically different, share several molecular features, as described in this review and schematized in Figure 4.

A complex interaction between RNAopathy, spliceopathy, and proteinopathy other than tauopathy has also been observed in other neurological diseases (Figure 4). Although these pathologies differ according to the nature and length of the microsatellite repeats, the aggregated proteins, clinical symptoms, and histological features, this interaction between RNAopathy, spliceopathy, and proteinopathy might be an essential inducer of the pathological mechanisms specific for neurological deregulation. Given the association between tauopathy, spliceopathy and RNAopathy in $\mathrm{DM}$, it would be interesting to determine whether tauopathies are also associated with other diseases involving microsatellite expansions and investigate whether this association is not specific to DM but is rather a more global mechanism in which spliceopathy, RNAopathy, and proteinopathy converge.

\section{ACKNOWLEDGMENTS}

This work was supported by funding from INSERM, CNRS, IMPRT, University of Lille Nord de France, Lille County Hospital (CHRU-Lille), DISTALZ (Development of Innovative Strategies for a Transdisciplinary approach to ALZheimer's disease) (Excellence Laboratory), FRM (Fondation pour la Recherche médicale), AFM, and ANR Neurosplice of Tau. The authors would like to thank Dr. de Munain for the DM1 tissue slices, Raphaelle Caillierez and Sabiha Eddarkaoui for assistance with immunohistochemistry.

\section{REFERENCES}

Abraham, R., Sims, R., Carroll, L., Hollingworth, P., O’Donovan, M. C., Williams, J., et al. (2009). An association study of common variation at the MAPT locus 
with late-onset Alzheimer's disease. Am. J. Med. Genet. B Neuropsychiatr. Genet. 150B, 1152-1155. doi: 10.1002/ajmg.b.30951

Alonso, A., Zaidi, T., Novak, M., Grundke-Iqbal, I., and Iqbal, K. (2001). Hyperphosphorylation induces self-assembly of tau into tangles of paired helical filaments/straight filaments. Proc. Natl. Acad. Sci. U.S.A. 98, 6923-6928. doi: 10.1073/pnas.121119298

Amadoro, G., Ciotti, M. T., Costanzi, M., Cestari, V., Calissano, P., and Canu, N. (2006). NMDA receptor mediates tau-induced neurotoxicity by calpain and ERK/MAPK activation. Proc. Natl. Acad. Sci. U.S.A. 103, 2892-2897. doi: 10.1073/pnas.0511065103

Amador-Ortiz, C., Lin, W. L., Ahmed, Z., Personett, D., Davies, P., Duara, R., et al. (2007). TDP-43 immunoreactivity in hippocampal sclerosis and Alzheimer's disease. Ann. Neurol. 61, 435-445. doi: 10.1002/ana.21154

Anderson, C. M., Henry, R. R., Knudson, P. E., Olefsky, J. M., and Webster, N. J. (1993). Relative expression of insulin receptor isoforms does not differ in lean, obese, and noninsulin-dependent diabetes mellitus subjects. J. Clin. Endocrinol. Metab. 76, 1380-1382. doi: 10.1210/jc.76.5.1380

Andreadis, A. (2005). Tau gene alternative splicing: expression patterns, regulation and modulation of function in normal brain and neurodegenerative diseases. Biochim. Biophys. Acta 1739, 91-103. doi: 10.1016/j.bbadis.2004.08.010

Antonini, G., Mainero, C., Romano, A., Giubilei, F., Ceschin, V., Gragnani, F., et al. (2004). Cerebral atrophy in myotonic dystrophy: a voxel based morphometric study. J. Neurol. Neurosurg. Psychiatr. 75, 1611-1613. doi: 10.1136/jnnp.2003.032417

Antonini, G., Soscia, F., Giubilei, F., De Carolis, A., Gragnani, F., and Morino, S. (2006). Health-related quality of life in myotonic dystrophy type 1 and its relationship with cognitive and emotional functioning. J. Rehabil. Med. 38, 181-185. doi: 10.1080/16501970500477967

Arikan, M. C., Memmott, J., Broderick, J. A., Lafyatis, R., Screaton, G., Stamm, S., et al. (2002). Modulation of the membrane-binding projection domain of tau protein: splicing regulation of exon 3. Brain Res. Mol. Brain Res. 101, 109-121. doi: 10.1016/S0169-328X(02)00178-X

Axford, M. M., and Pearson, C. E. (2013). Illuminating CNS and cognitive issues in myotonic dystrophy: Workshop report. Neuromuscul. Disord. 23, 370-374. doi: 10.1016/j.nmd.2013.01.003

Bai, B., Hales, C. M., Chen, P. C., Gozal, Y., Dammer, E. B., Fritz, J. J., et al. (2013). U1 small nuclear ribonucleoprotein complex and RNA splicing alterations in Alzheimer's disease. Proc. Natl. Acad. Sci. U.S.A. 110, 16562-16567. doi: 10.1073/pnas.13102 49110

Baig, S., van Helmond, Z., and Love, S. (2009). Tau hyperphosphorylation affects Smad 2/3 translocation. Neuroscience 163, 561-570. doi: 10.1016/j.neuroscience.2009.06.045

Baker, M., Graff-Radford, D., Wavrant DeVrieze, F., Graff-Radford, N., Petersen, R. C., Kokmen, E., et al. (2000). No association between TAU haplotype and Alzheimer's disease in population or clinic based series or in familial disease. Neurosci. Lett. 285, 147-149. doi: 10.1016/S0304-3940(00)01057-0

Ball, M. J. (1977). Neuronal loss, neurofibrillary tangles and granulovacuolar degeneration in the hippocampus with ageing and dementia. A quantitative study. Acta Neuropathol. 37, 111-118. doi: 10.1007/BF00692056

Ball, M. J., and Lo, P. (1977). Granulovacuolar degeneration in the ageing brain and in dementia. J. Neuropathol. Exp. Neurol. 36, 474-487. doi: 10.1097/00005072197705000-00006

Barnby, G., Abbott, A., Sykes, N., Morris, A., Weeks, D. E., Mott, R., et al. (2005). Candidate-gene screening and association analysis at the autism-susceptibility locus on chromosome 16p: evidence of association at GRIN2A and ABAT. Am. J. Hum. Genet. 76, 950-966. doi: 10.1086/430454

Batra, R., Charizanis, K., and Swanson, M. S. (2010). Partners in crime: bidirectional transcription in unstable microsatellite disease. Hum. Mol. Genet. 19, R77-R82. doi: 10.1093/hmg/ddq132

Belfiore, A., Frasca, F., Pandini, G., Sciacca, L., and Vigneri, R. (2009). Insulin receptor isoforms and insulin receptor/insulin-like growth factor receptor hybrids in physiology and disease. Endocr. Rev. 30, 586-623. doi: 10.1210/er. 2008-0047

Benecke, H., Flier, J. S., and Moller, D. E. (1992). Alternatively spliced variants of the insulin receptor protein. Expression in normal and diabetic human tissues. J. Clin. Invest. 89, 2066-2070. doi: 10.1172/JCI115819

Bennett, D. A., Schneider, J. A., Wilson, R. S., Bienias, J. L., and Arnold, S. E. (2004). Neurofibrillary tangles mediate the association of amyloid load with clinical
Alzheimer disease and level of cognitive function. Arch. Neurol. 61, 378-384. doi: 10.1001/archneur.61.3.378

Berg, L., Mckeel, D. W. Jr., Miller, J. P., Storandt, M., Rubin, E. H., Morris, J. C., et al. (1998). Clinicopathologic studies in cognitively healthy aging and Alzheimer's disease: relation of histologic markers to dementia severity, age, sex, and apolipoprotein E genotype. Arch. Neurol. 55, 326-335. doi: 10.1001/archneur.55.3.326

Berson, A., Barbash, S., Shaltiel, G., Goll, Y., Hanin, G., Greenberg, D. S., et al. (2012). Cholinergic-associated loss of hnRNP-A/B in Alzheimer's disease impairs cortical splicing and cognitive function in mice. ЕMBO Mol. Med. 4, 730-742. doi: 10.1002/emmm.201100995

Bhalla, K., Phillips, H. A., Crawford, J., McKenzie, O. L., Mulley, J. C., Eyre, H., et al. (2004). The de novo chromosome 16 translocations of two patients with abnormal phenotypes (mental retardation and epilepsy) disrupt the A2BP1 gene. J. Hum. Genet. 49, 308-311. doi: 10.1007/s10038-004-0145-4

Bieniek, K. F., Murray, M. E., Rutherford, N. J., Castanedes-Casey, M., DeJesusHernandez, M., Liesinger, A. M., et al. (2013). Tau pathology in frontotemporal lobar degeneration with C9ORF72 hexanucleotide repeat expansion. Acta Neuropathol. 125, 289-302. doi: 10.1007/s00401-012-1048-7

Bitel, C. L., Kasinathan, C., Kaswala, R. H., Klein, W. L., and Frederikse, P. H. (2012). Amyloid-beta and tau pathology of Alzheimer's disease induced by diabetes in a rabbit animal model. J. Alzheimers. Dis. 32, 291-305. doi: 10.3233/JAD-2012-120571

Blennow, K., and Hampel, H. (2003). CSF markers for incipient Alzheimer's disease. Lancet Neurol. 2, 605-613. doi: 10.1016/S1474-4422(03)00530-1

Bombois, S., Duhamel, A., Salleron, J., Deramecourt, V., Mackowiak, M. A., Deken, V., et al. (2013). A new decision tree combining Abeta 1-42 and pTau levels in Alzheimer's diagnosis. Curr. Alzheimer Res. 10, 357-364. doi: $10.2174 / 1567205011310040002$

Bosco, D., Fava, A., Plastino, M., Montalcini, T., and Pujia, A. (2011). Possible implications of insulin resistance and glucose metabolism in Alzheimer's disease pathogenesis. J. Cell. Mol. Med. 15, 1807-1821. doi: 10.1111/j.15824934.2011.01318.x

Bose, J. K., Wang, I. F., Hung, L., Tarn, W. Y., and Shen, C. K. (2008). TDP-43 overexpression enhances exon 7 inclusion during the survival of motor neuron premRNA splicing. J. Biol. Chem. 283, 28852-28859. doi: 10.1074/jbc.M805376200

Boutajangout, A., Boom, A., Leroy, K., and Brion, J. P. (2004). Expression of tau mRNA and soluble tau isoforms in affected and non-affected brain areas in Alzheimer's disease. FEBS Lett. 576, 183-189. doi: 10.1016/j.febslet.2004.09.011

Braak, H., and Braak, E. (1991). Neuropathological stageing of Alzheimer-related changes. Acta Neuropathol. 82, 239-259. doi: 10.1007/BF00308809

Brook, J. D., McCurrach, M. E., Harley, H. G., Buckler, A. J., Church, D., Aburatani, H., et al. (1992). Molecular basis of myotonic dystrophy: expansion of a trinucleotide (CTG) repeat at the $3^{\prime}$ end of a transcript encoding a protein kinase family member. Cell 68, 799-808. doi: 10.1016/0092-8674(92)90154-5

Bruehl, H., Sweat, V., Hassenstab, J., Polyakov, V., and Convit, A. (2010). Cognitive impairment in nondiabetic middle-aged and older adults is associated with insulin resistance. J. Clin. Exp. Neuropsychol. 32, 487-493. doi: $10.1080 / 13803390903224928$

Buee, L., Troquier, L., Burnouf, S., Belarbi, K., Van Der Jeugd, A., Ahmed, T., et al. (2010). From tau phosphorylation to tau aggregation: what about neuronal death? Biochem. Soc. Trans. 38, 967-972. doi: 10.1042/BST0380967

Bungener, C., Jouvent, R., and Delaporte, C. (1998). Psychopathological and emotional deficits in myotonic dystrophy. J. Neurol. Neurosurg. Psychiatr. 65, 353-356. doi: 10.1136/jnnp.65.3.353

Bunker, J. M., Wilson, L., Jordan, M. A., and Feinstein, S. C. (2004). Modulation of microtubule dynamics by tau in living cells: implications for development and neurodegeneration. Mol. Biol. Cell 15, 2720-2728. doi: 10.1091/mbc.E0401-0062

Buratti, E., Brindisi, A., Giombi, M., Tisminetzky, S., Ayala, Y. M., and Baralle, F. E. (2005). TDP-43 binds heterogeneous nuclear ribonucleoprotein A/B through its C-terminal tail: an important region for the inhibition of cystic fibrosis transmembrane conductance regulator exon 9 splicing. J. Biol. Chem. 280, 37572-37584. doi: 10.1074/jbc.M505557200

Caffrey, T. M., Joachim, C., and Wade-Martins, R. (2008). Haplotype-specific expression of the N-terminal exons 2 and 3 at the human MAPT locus. Neurobiol. Aging 29, 1923-1929. doi: 10.1016/j.neurobiolaging.2007.05.002

Caillierez, R., Begard, S., Lecolle, K., Deramecourt, V., Zommer, N., Dujardin, S., et al. (2013). Lentiviral delivery of the human wild-type tau protein mediates 
a slow and progressive neurodegenerative tau pathology in the rat brain. Mol. Ther. 21, 1358-1368. doi: 10.1038/mt.2013.66

Carrasquillo, M. M., Belbin, O., Hunter, T. A., Ma, L., Bisceglio, G. D., Zou, F., et al. (2011). Replication of BIN1 association with Alzheimer's disease and evaluation of genetic interactions. J. Alzheimers. Dis. 24, 751-758. doi: 10.3233/JAD-2011101932

Censori, B., Provinciali, L., Danni, M., Chiaramoni, L., Maricotti, M., Foschi, N., et al. (1994). Brain involvement in myotonic dystrophy: MRI features and their relationship to clinical and cognitive conditions. Acta Neurol. Scand. 90, 211-217. doi: 10.1111/j.1600-0404.1994.tb02708.x

Chandler, L. J., Harris, R. A., and Crews, F. T. (1998). Ethanol tolerance and synaptic plasticity. Trends Pharmacol. Sci. 19, 491-495. doi: 10.1016/S01656147(98)01268-1

Chapuis, J., Hansmannel, F., Gistelinck, M., Mounier, A., Van Cauwenberghe, C., Kolen, K. V., et al. (2013). Increased expression of BIN1 mediates Alzheimer genetic risk by modulating tau pathology. Mol. Psychiatry 18, 1225-1234. doi: 10.1038/mp.2013.1

Charizanis, K., Lee, K. Y., Batra, R., Goodwin, M., Zhang, C., Yuan, Y., et al. (2012). Muscleblind-like 2-mediated alternative splicing in the developing brain and dysregulation in myotonic dystrophy. Neuron 75, 437-450. doi: 10.1016/j.neuron.2012.05.029

Charlet-B. N., Savkur, R. S., Singh, G., Philips, A. V., Grice, E. A., and Cooper, T. A. (2002). Loss of the muscle-specific chloride channel in type 1 myotonic dystrophy due to misregulated alternative splicing. Mol. Cell 10, 45-53. doi: 10.1016/S1097-2765(02)00572-5

Cho, D. H., and Tapscott, S. J. (2007). Myotonic dystrophy: emerging mechanisms for DM1 and DM2. Biochim. Biophys. Acta 1772, 195-204. doi: 10.1016/j.bbadis.2006.05.013

Clavaguera, F., Akatsu, H., Fraser, G., Crowther, R. A., Frank, S., Hench, J., et al. (2013). Brain homogenates from human tauopathies induce tau inclusions in mouse brain. Proc. Natl. Acad. Sci. U.S.A. 110, 9535-9540. doi: 10.1073/pnas. 1301175110

Clavaguera, F., Bolmont, T., Crowther, R. A., Abramowski, D., Frank, S., Probst, A., et al. (2009). Transmission and spreading of tauopathy in transgenic mouse brain. Nat. Cell Biol. 11, 909-913. doi: 10.1038/ncb1901

Cohen, O. S., McCoy, S. Y., Middleton, F. A., Bialosuknia, S., Zhang-James, Y., Liu, L., et al. (2012). Transcriptomic analysis of postmortem brain identifies dysregulated splicing events in novel candidate genes for schizophrenia. Schizophr. Res. 142, 188-199. doi: 10.1016/j.schres.2012.09.015

Combs, B., Voss, K., and Gamblin, T. C. (2011). Pseudohyperphosphorylation has differential effects on polymerization and function of tau isoforms. Biochemistry 50, 9446-9456. doi: 10.1021/bi2010569

Connell, J. W., Rodriguez-Martin, T., Gibb, G. M., Kahn, N. M., Grierson, A. J., Hanger, D. P., et al. (2005). Quantitative analysis of tau isoform transcripts in sporadic tauopathies. Brain Res. Mol. Brain Res. 137, 104-109. doi: 10.1016/j.molbrainres.2005.02.014

Conrad, C., Zhu, J., Schoenfeld, D., Fang, Z., Ingelsson, M., Stamm, S., et al. (2007). Single molecule profiling of tau gene expression in Alzheimer's disease. J. Neurochem. 103, 1228-1236. doi: 10.1111/j.1471-4159.2007.04857.x

Cooper-Knock, J., Kirby, J., Ferraiuolo, L., Heath, P. R., Rattray, M., and Shaw, P. J. (2012). Gene expression profiling in human neurodegenerative disease. Nat. Rev. Neurol. 8, 518-530. doi: 10.1038/nrneurol.2012.156

Couchie, D., Mavilia, C., Georgieff, I. S., Liem, R. K., Shelanski, M. L., and Nunez, J. (1992). Primary structure of high molecular weight tau present in the peripheral nervous system. Proc. Natl. Acad. Sci. U.S.A. 89, 4378-4381. doi: 10.1073/pnas.89.10.4378

Cowan, C. M., and Mudher, A. (2013). Are tau aggregates toxic or protective in tauopathies? Front. Neurol. 4:114. doi: 10.3389/fneur.2013.00114

D'Angelo, M. G., and Bresolin, N. (2003). Report of the 95th European Neuromuscular Centre (ENMC) sponsored international workshop cognitive impairment in neuromuscular disorders, Naarden, The Netherlands 13-15 July 2001. Neuromuscul. Disord. 13, 72-79. doi: 10.1016/S0960-8966(02)00155-4

Day, J. W., and Ranum, L. P. (2005). RNA pathogenesis of the myotonic dystrophies. Neuromuscul. Disord. 15, 5-16. doi: 10.1016/j.nmd.2004.09.012

De Calignon, A., Polydoro, M., Suarez-Calvet, M., William, C., Adamowicz, D. H., Kopeikina, K. J., et al. (2012). Propagation of tau pathology in a model of early Alzheimer's disease. Neuron 73, 685-697. doi: 10.1016/j.neuron.2011.11.033

De Felice, F. G., Velasco, P. T., Lambert, M. P., Viola, K., Fernandez, S. J., Ferreira, S. T., et al. (2007). Abeta oligomers induce neuronal oxidative stress through an $\mathrm{N}$-methyl-D-aspartate receptor-dependent mechanism that is blocked by the Alzheimer drug memantine. J. Biol. Chem. 282, 11590-11601. doi: 10.1074/jbc.M607483200

DeJesus-Hernandez, M., Mackenzie, I. R., Boeve, B. F., Boxer, A. L., Baker, M. Rutherford, N. J., et al. (2011). Expanded GGGGCC hexanucleotide repeat in noncoding region of C9ORF72 causes chromosome 9p-linked FTD and ALS. Neuron 72, 245-256. doi: 10.1016/j.neuron.2011.09.011

Delacourte, A., David, J. P., Sergeant, N., Buee, L., Wattez, A., Vermersch, P., et al. (1999). The biochemical pathway of neurofibrillary degeneration in aging and Alzheimer's disease. Neurology 52, 1158-1165. doi: 10.1212/WNL.52.6.1158

de Mezer, M., Wojciechowska, M., Napierala, M., Sobczak, K., and Krzyzosiak, W. J. (2011). Mutant CAG repeats of Huntingtin transcript fold into hairpins, form nuclear foci and are targets for RNA interference. Nucleic Acids Res. 39, 3852-3863. doi: 10.1093/nar/gkq1323

Dhaenens, C. M., Schraen-Maschke, S., Tran, H., Vingtdeux, V., Ghanem, D., Leroy, O., et al. (2008). Overexpression of MBNL1 fetal isoforms and modified splicing of Tau in the DM1 brain: two individual consequences of CUG trinucleotide repeats. Exp. Neurol. 210, 467-478. doi: 10.1016/j.expneurol.2007.11.020

Dhaenens, C. M., Tran, H., Frandemiche, M. L., Carpentier, C., Schraen-Maschke, S., Sistiaga, A., et al. (2011). Mis-splicing of Tau exon 10 in myotonic dystrophy type 1 is reproduced by overexpression of CELF2 but not by MBNL1 silencing. Biochim. Biophys. Acta 1812, 732-742. doi: 10.1016/j.bbadis.2011.03.010

Di Costanzo, A., Di Salle, F., Santoro, L., Bonavita, V., and Tedeschi, G., (2001) Dilated Virchow-Robin spaces in myotonic dystrophy: frequency, extent and significance. Eur. Neurol. 46, 131-139. doi: 10.1159/000050786

Dixit, R., Ross, J. L., Goldman, Y. E., and Holzbaur, E. L. (2008). Differential regulation of dynein and kinesin motor proteins by tau. Science 319, 1086-1089. doi: 10.1126/science. 1152993

Dominguez, E., Chin, T. Y., Chen, C. P., and Wu, T. Y. (2011). Management of moderate to severe Alzheimer's disease: focus on memantine. Taiwan. J. Obstet. Gynecol. 50, 415-423. doi: 10.1016/j.tjog.2011.10.004

Donev, R., Kolev, M., Millet, B., and Thome, J. (2009). Neuronal death in Alzheimer's disease and therapeutic opportunities. J. Cell. Mol. Med. 13, 4329-4348. doi: 10.1111/j.1582-4934.2009.00889.x

Dou, F., Netzer, W. J., Tanemura, K., Li, F., Hartl, F. U., Takashima, A., et al. (2003). Chaperones increase association of tau protein with microtubules. Proc. Natl. Acad. Sci. U.S.A. 100, 721-726. doi: 10.1073/pnas.242720499

Dreumont, N., Hardy, S., Behm-Ansmant, I., Kister, L., Branlant, C., Stevenin, J., et al. (2010). Antagonistic factors control the unproductive splicing of SC35 terminal intron. Nucleic Acids Res. 38, 1353-1366. doi: 10.1093/nar/gkp1086

Duyckaerts, C., Bennecib, M., Grignon, Y., Uchihara, T., He, Y., Piette, F., et al. (1997). Modeling the relation between neurofibrillary tangles and intellectual status. Neurobiol. Aging 18, 267-273. doi: 10.1016/S0197-4580(97)80306-5

Echavarri, C., Burgmans, S., Caballero, M. C., Garcia-Bragado, F., Verhey, F. R., and Uylings, H. B. (2012). Co-occurrence of different pathologies in dementia: implications for dementia diagnosis. J. Alzheimers. Dis. 30, 909-917. doi: 10.3233/JAD-2012-111400

Ekstrom, A. B., Hakenas-Plate, L., Samuelsson, L., Tulinius, M., and Wentz, E. (2008). Autism spectrum conditions in myotonic dystrophy type 1: a study on 57 individuals with congenital and childhood forms. Am. J. Med. Genet. B Neuropsychiatr. Genet. 147B, 918-926. doi: 10.1002/ajmg.b.30698

Fallini, C., Bassell, G. J., and Rossoll, W. (2012). The ALS disease protein TDP-43 is actively transported in motor neuron axons and regulates axon outgrowth. Hum. Mol. Genet. 21, 3703-3718. doi: 10.1093/hmg/dds205

Fardaei, M., Larkin, K., Brook, J. D., and Hamshere, M. G. (2001). In vivo colocalisation of MBNL protein with DMPK expanded-repeat transcripts. Nucleic Acids Res. 29, 2766-2771. doi: 10.1093/nar/29.13.2766

Fardaei, M., Rogers, M. T., Thorpe, H. M., Larkin, K., Hamshere, M. G., Harper, P. S., et al. (2002). Three proteins, MBNL, MBLL and MBXL, co-localize in vivo with nuclear foci of expanded-repeat transcripts in DM1 and DM2 cells. Hum. Mol. Genet. 11, 805-814. doi: 10.1093/hmg/11.7.805

Feng, D., and Xie, J. (2013). Aberrant splicing in neurological diseases. Wiley Interdiscip. Rev. RNA 4, 631-649. doi: 10.1002/wrna.1184

Fiesel, F. C., Weber, S. S., Supper, J., Zell, A., and Kahle, P. J. (2012). TDP-43 regulates global translational yield by splicing of exon junction complex component SKAR. Nucleic Acids Res. 40, 2668-2682. doi: 10.1093/nar/gkr1082

Freibaum, B. D., Chitta, R. K., High, A. A., and Taylor, J. P. (2010). Global analysis of TDP-43 interacting proteins reveals strong association with RNA splicing and translation machinery. J. Proteome Res. 9, 1104-1120. doi: 10.1021/pr901076y 
Frisardi, V., Solfrizzi, V., Seripa, D., Capurso, C., Santamato, A., Sancarlo, D., et al. (2010). Metabolic-cognitive syndrome: a cross-talk between metabolic syndrome and Alzheimer's disease. Ageing Res. Rev. 9, 399-417. doi: 10.1016/j.arr.2010.04.007

Fu, Y. H., Friedman, D. L., Richards, S., Pearlman, J. A., Gibbs, R. A., Pizzuti, A., et al. (1993). Decreased expression of myotonin-protein kinase messenger RNA and protein in adult form of myotonic dystrophy. Science 260, 235-238. doi: 10.1126/science.8469976

Fugier, C., Klein, A. F., Hammer, C., Vassilopoulos, S., Ivarsson, Y., Toussaint, A., et al. (2011). Misregulated alternative splicing of BIN1 is associated with $\mathrm{T}$ tubule alterations and muscle weakness in myotonic dystrophy. Nat. Med. 17, 720-725. doi: 10.1038/nm.2374

Fukuda, H., Horiguchi, J., Ono, C., Ohshita, T., Takaba, J., and Ito, K. (2005). Diffusion tensor imaging of cerebral white matter in patients with myotonic dystrophy. Acta Radiol. 46, 104-109. doi: 10.1080/02841850510015974

Funk, K. E., Mrak, R. E., and Kuret, J. (2011). Granulovacuolar degeneration (GVD) bodies of Alzheimer's disease (AD) resemble late-stage autophagic organelles. Neuropathol. Appl. Neurobiol. 37, 295-306. doi: 10.1111/j.13652990.2010.01135.x

Garcia-Murias, M., Quintans, B., Arias, M., Seixas, A. I., Cacheiro, P., Tarrio, R., et al. (2012). "Costa da Morte" ataxia is spinocerebellar ataxia 36: clinical and genetic characterization. Brain 135, 1423-1435. doi: 10.1093/brain/aws069

Georgieff, I. S., Liem, R. K., Couchie, D., Mavilia, C., Nunez, J., and Shelanski, M. L. (1993). Expression of high molecular weight tau in the central and peripheral nervous systems. J. Cell Sci. 105(Pt 3), 729-737.

Ghoshal, N., Garcia-Sierra, F., Wuu, J., Leurgans, S., Bennett, D. A., Berry, R. W., et al. (2002). Tau conformational changes correspond to impairments of episodic memory in mild cognitive impairment and Alzheimer's disease. Exp. Neurol. 177, 475-493. doi: 10.1006/exnr.2002.8014

Giannakopoulos, P., Herrmann, F. R., Bussiere, T., Bouras, C., Kovari, E., Perl, D. P., et al. (2003). Tangle and neuron numbers, but not amyloid load, predict cognitive status in Alzheimer's disease. Neurology 60, 1495-1500. doi: 10.1212/01.WNL.0000063311.58879.01

Gibb, W. R., Mountjoy, C. Q., Mann, D. M., and Lees, A. J. (1989). A pathological study of the association between Lewy body disease and Alzheimer's disease. J. Neurol. Neurosurg. Psychiatr. 52, 701-708. doi: 10.1136/jnnp.52.6.701

Glatz, D. C., Rujescu, D., Tang, Y., Berendt, F. J., Hartmann, A. M., Faltraco, F., et al. (2006). The alternative splicing of tau exon 10 and its regulatory proteins CLK2 and TRA2-BETA1 changes in sporadic Alzheimer's disease. J. Neurochem. 96, 635-644. doi: 10.1111/j.1471-4159.2005.03552.x

Gomes-Pereira, M., Foiry, L., Nicole, A., Huguet, A., Junien, C., Munnich, A., et al. (2007). CTG trinucleotide repeat "big jumps": large expansions, small mice. PLoS Genet. 3:e52. doi: 10.1371/journal.pgen.0030052

Goode, B. L., and Feinstein, S. C. (1994). Identification of a novel microtubule binding and assembly domain in the developmentally regulated inter-repeat region of tau. J. Cell Biol. 124, 769-782. doi: 10.1083/jcb.124.5.769

Hansen, T., Bjorbaek, C., Vestergaard, H., Gronskov, K., Bak, J. F., and Pedersen, O. (1993). Expression of insulin receptor spliced variants and their functional correlates in muscle from patients with non-insulin-dependent diabetes mellitus. J. Clin. Endocrinol. Metab. 77, 1500-1505. doi: 10.1210/jc.77.6.1500

Harley, H. G., Rundle, S. A., Macmillan, J. C., Myring, J., Brook, J. D., Crow, S., et al. (1993). Size of the unstable CTG repeat sequence in relation to phenotype and parental transmission in myotonic dystrophy. Am. J. Hum. Genet. 52, 1164-1174.

Herukka, S. K., Hallikainen, M., Soininen, H., and Pirttila, T. (2005). CSF Abeta42 and tau or phosphorylated tau and prediction of progressive mild cognitive impairment. Neurology 64, 1294-1297. doi: 10.1212/01.WNL.0000156914.16988.56

Ho, T. H., Charlet, B. N., Poulos, M. G., Singh, G., Swanson, M. S., and Cooper, T. A. (2004). Muscleblind proteins regulate alternative splicing. EMBO J. 23, 3103-3112. doi: 10.1038/sj.emboj.7600300

Holmes, S. E., O’Hearn, E., Rosenblatt, A., Callahan, C., Hwang, H. S., IngersollAshworth, R. G., et al. (2001). A repeat expansion in the gene encoding junctophilin-3 is associated with Huntington disease-like 2. Nat. Genet. 29, 377-378. doi: 10.1038/ng760

Huang, Y., and Mucke, L. (2012). Alzheimer mechanisms and therapeutic strategies. Cell 148, 1204-1222. doi: 10.1016/j.cell.2012.02.040

Huang, Z., Bodkin, N. L., Ortmeyer, H. K., Hansen, B. C., and Shuldiner, A. R. (1994). Hyperinsulinemia is associated with altered insulin receptor mRNA splicing in muscle of the spontaneously obese diabetic rhesus monkey. J. Clin. Invest. 94, 1289-1296. doi: 10.1172/JCI117447

Huang, Z., Bodkin, N. L., Ortmeyer, H. K., Zenilman, M. E., Webster, N. J., Hansen, B. C., et al. (1996). Altered insulin receptor messenger ribonucleic acid splicing in liver is associated with deterioration of glucose tolerance in the spontaneously obese and diabetic rhesus monkey: analysis of controversy between monkey and human studies. J. Clin. Endocrinol. Metab. 81, 1552-1556. doi: 10.1210/jc.81.4.1552

Huguet, A., Medja, F., Nicole, A., Vignaud, A., Guiraud-Dogan, C., Ferry, A., et al. (2012). Molecular, physiological, and motor performance defects in DMSXL mice carrying $>1,000$ CTG repeats from the human DM1 locus. PLoS Genet. 8:e1003043. doi: 10.1371/journal.pgen.1003043

Hund, E., Jansen, O., Koch, M. C., Ricker, K., Fogel, W., Niedermaier, N., et al. (1997). Proximal myotonic myopathy with MRI white matter abnormalities of the brain. Neurology 48, 33-37. doi: 10.1212/WNL.48.1.33

Ikeda, Y., Ohta, Y., Kobayashi, H., Okamoto, M., Takamatsu, K., Ota, T., et al. (2012). Clinical features of SCA36: a novel spinocerebellar ataxia with motor neuron involvement (Asidan). Neurology 79, 333-341. doi: 10.1212/WNL.0b013e318260436f

Ingelsson, M., Ramasamy, K., Cantuti-Castelvetri, I., Skoglund, L., Matsui, T., Orne, J., et al. (2006). No alteration in tau exon 10 alternative splicing in tangle-bearing neurons of the Alzheimer's disease brain. Acta Neuropathol. 112, 439-449. doi: 10.1007/s00401-006-0095-3

Itoh, K., Mitani, M., Kawamoto, K., Futamura, N., Funakawa, I., Jinnai, K., et al. (2010). Neuropathology does not Correlate with Regional Differences in the Extent of Expansion of CTG Repeats in the Brain with Myotonic Dystrophy Type 1. Acta Histochem. Cytochem. 43, 149-156. doi: 10.1267/ahc.10019

Iwahashi, C. K., Yasui, D. H., An, H. J., Greco, C. M., Tassone, F., Nannen, K., et al. (2006). Protein composition of the intranuclear inclusions of FXTAS. Brain 129, 256-271. doi: 10.1093/brain/awh650

Jaekel, B., Muhlberg, K., Garcia de Arriba, S., Reichenbach, A., Verdaguer, E., Pallas, M., et al. (2006). Neuroprotection associated with alternative splicing of NMDA receptors in rat cortical neurons. Br. J. Pharmacol. 147, 622-633. doi: 10.1038/sj.bjp.0706471

James, B. D., Bennett, D. A., Boyle, P. A., Leurgans, S., and Schneider, J. A. (2012). Dementia from Alzheimer disease and mixed pathologies in the oldest old. JAMA 307, 1798-1800. doi: 10.1001/jama.2012.3556

Jeganathan, S., von Bergen, M., Mandelkow, E. M., and Mandelkow, E. (2008). The natively unfolded character of tau and its aggregation to Alzheimer-like paired helical filaments. Biochemistry 47, 10526-10539. doi: 10.1021/bi800783d

Jiang, H., Mankodi, A., Swanson, M. S., Moxley, R. T., and Thornton, C. A. (2004) Myotonic dystrophy type 1 is associated with nuclear foci of mutant RNA, sequestration of muscleblind proteins and deregulated alternative splicing in neurons. Hum. Mol. Genet. 13, 3079-3088. doi: 10.1093/hmg/ddh327

Jog, S. P., Paul, S., Dansithong, W., Tring, S., Comai, L., and Reddy, S. (2012). RNA Splicing Is Responsive to MBNL1 Dose. PLoS ONE 7:e48825. doi: 10.1371/journal.pone. 0048825

Johnson, S. A., Rogers, J., and Finch, C. E. (1989). APP-695 transcript prevalence is selectively reduced during Alzheimer's disease in cortex and hippocampus but not in cerebellum. Neurobiol. Aging 10, 755-760. doi: 10.1016/01974580(89)90017-1

Jolivalt, C. G., Hurford, R., Lee, C. A., Dumaop, W., Rockenstein, E., and Masliah, E. (2010). Type 1 diabetes exaggerates features of Alzheimer's disease in APP transgenic mice. Exp. Neurol. 223, 422-431. doi: 10.1016/j.expneurol.2009. 11.005

Jung, H. J., Park, S. S., Mok, J. O., Lee, T. K., Park, C. S., and Park, S. A. (2011). Increased expression of three-repeat isoforms of tau contributes to tau pathology in a rat model of chronic type 2 diabetes. Exp. Neurol. 228, 232-241. doi: 10.1016/j.expneurol.2011.01.012

Kabashi, E., Valdmanis, P. N., Dion, P., Spiegelman, D., McConkey, B. J., Vande Velde, C., et al. (2008). TARDBP mutations in individuals with sporadic and familial amyotrophic lateral sclerosis. Nat. Genet. 40, 572-574. doi: 10.1038/ng.132

Kalsotra, A., Xiao, X., Ward, A. J., Castle, J. C., Johnson, J. M., Burge, C. B., et al. (2008). A postnatal switch of CELF and MBNL proteins reprograms alternative splicing in the developing heart. Proc. Natl. Acad. Sci. U.S.A. 105, 20333-20338. doi: 10.1073/pnas.0809045105

Kaminsky, P., Poussel, M., Pruna, L., Deibener, J., Chenuel, B., and Brembilla-Perrot, B. (2011). Organ dysfunction and muscular disability 
in myotonic dystrophy type 1. Medicine (Baltimore) 90, 262-268. doi: 10.1097/MD.0b013e318226046b

Kanaan, N. M., Morfini, G. A., LaPointe, N. E., Pigino, G. F., Patterson, K. R., Song, Y., et al. (2011). Pathogenic forms of tau inhibit kinesin-dependent axonal transport through a mechanism involving activation of axonal phosphotransferases. J. Neurosci. 31, 9858-9868. doi: 10.1523/JNEUROSCI.056011.2011

Kanaan, N. M., Morfini, G., Pigino, G., LaPointe, N. E., Andreadis, A., Song, Y., et al. (2012). Phosphorylation in the amino terminus of tau prevents inhibition of anterograde axonal transport. Neurobiol. Aging 33, 826.e15-826.e30. doi: 10.1016/j.neurobiolaging.2011.06.006

Kanadia, R. N., Johnstone, K. A., Mankodi, A., Lungu, C., Thornton, C. A., Esson, D., et al. (2003). A muscleblind knockout model for myotonic dystrophy. Science 302, 1978-1980. doi: 10.1126/science. 1088583

Kanai, Y., Chen, J., and Hirokawa, N. (1992). Microtubule bundling by tau proteins in vivo: analysis of functional domains. EMBO J. 11, 3953-3961.

Kassubek, J., Juengling, F. D., Hoffmann, S., Rosenbohm, A., Kurt, A., Jurkat-Rott, K., et al. (2003). Quantification of brain atrophy in patients with myotonic dystrophy and proximal myotonic myopathy: a controlled 3-dimensional magnetic resonance imaging study. Neurosci. Lett. 348, 73-76. doi: 10.1016/S03043940(03)00740-7

Kawahara, Y., and Mieda-Sato, A. (2012). TDP-43 promotes microRNA biogenesis as a component of the Drosha and Dicer complexes. Proc. Natl. Acad. Sci. U.S.A. 109, 3347-3352. doi: 10.1073/pnas.1112427109

Ke, Y., Dramiga, J., Schutz, U., Kril, J. J., Ittner, L. M., Schroder, H., et al. (2012). Tau-mediated nuclear depletion and cytoplasmic accumulation of SFPQ in Alzheimer's and Pick's disease. PLoS ONE 7:e35678. doi: 10.1371/journal.pone. 0035678

Kellerer, M., Sesti, G., Seffer, E., Obermaier-Kusser, B., Pongratz, D. E., Mosthaf, L., et al. (1993). Altered pattern of insulin receptor isotypes in skeletal muscle membranes of type 2 (non-insulin-dependent) diabetic subjects. Diabetologia 36, 628-632. doi: 10.1007/BF00404072

Kim, D. H., Langlois, M. A., Lee, K. B., Riggs, A. D., Puymirat, J., and Rossi, J. J. (2005). HnRNP H inhibits nuclear export of mRNA containing expanded CUG repeats and a distal branch point sequence. Nucleic Acids Res. 33, 3866-3874. doi: 10.1093/nar/gki698

Kim, W., Lee, S., and Hall, G. F. (2010). Secretion of human tau fragments resembling CSF-tau in Alzheimer's disease is modulated by the presence of the exon 2 insert. FEBS Lett. 584, 3085-3088. doi: 10.1016/j.febslet.2010.05.042

King, A., Al-Sarraj, S., Troakes, C., Smith, B. N., Maekawa, S., Iovino, M., et al. (2013). Mixed tau, TDP-43 and p62 pathology in FTLD associated with a C9ORF72 repeat expansion and p.Ala239Thr MAPT (tau) variant. Acta Neuropathol. 125, 303-310. doi: 10.1007/s00401-012-1050-0

Kino, Y., Washizu, C., Oma, Y., Onishi, H., Nezu, Y., Sasagawa, N., et al. (2009). MBNL and CELF proteins regulate alternative splicing of the skeletal muscle chloride channel CLCN1. Nucleic Acids Res. 37, 6477-6490. doi: 10.1093/nar/gkp681

Kiuchi, A., Otsuka, N., Namba, Y., Nakano, I., and Tomonaga, M. (1991). Presenile appearance of abundant Alzheimer's neurofibrillary tangles without senile plaques in the brain in myotonic dystrophy. Acta Neuropathol. 82, 1-5. doi: 10.1007/BF00310916

Klein, A. F., Gasnier, E., and Furling, D. (2011). Gain of RNA function in pathological cases: Focus on myotonic dystrophy. Biochimie 93, 2006-2012. doi: 10.1016/j.biochi.2011.06.028

Kornblum, C., Reul, J., Kress, W., Grothe, C., Amanatidis, N., Klockgether, T., et al. (2004). Cranial magnetic resonance imaging in genetically proven myotonic dystrophy type 1 and 2. J. Neurol. 251, 710-714. doi: 10.1007/s00415-0040408-1

Kuru, S., Sakai, M., Yoshida, M., Mimuro, M., and Hashizume, Y. (2013). Neurofibrillary tangles in the peripheral sympathetic ganglia of patients with myotonic dystrophy. Neuropathol. Appl. Neurobiol. 39, 585-588. doi: 10.1111/nan.12043

Kuyumcu-Martinez, N. M., and Cooper, T. A. (2006). Misregulation of alternative splicing causes pathogenesis in myotonic dystrophy. Prog. Mol. Subcell. Biol. 44, 133-159. doi: 10.1007/978-3-540-34449-0_7

Kuyumcu-Martinez, N. M., Wang, G. S., and Cooper, T. A. (2007). Increased steady-state levels of CUGBP1 in myotonic dystrophy 1 are due to PKC-mediated hyperphosphorylation. Mol. Cell 28, 68-78. doi: 10.1016/j.molcel.2007.07.027
Laberge, L., Gagnon, C., and Dauvilliers, Y. (2013). Daytime sleepiness and myotonic dystrophy. Curr. Neurol. Neurosci. Rep. 13, 340. doi: 10.1007/s11910013-0340-9

Ladd, A. N., Charlet, N., and Cooper, T. A. (2001). The CELF family of RNA binding proteins is implicated in cell-specific and developmentally regulated alternative splicing. Mol. Cell. Biol. 21, 1285-1296. doi: 10.1128/MCB.21.4.12851296.2001

Ladd, A. N., Nguyen, N. H., Malhotra, K., and Cooper, T. A. (2004). CELF6, a member of the CELF family of RNA-binding proteins, regulates musclespecific splicing enhancer-dependent alternative splicing. J. Biol. Chem. 279, 17756-17764. doi: 10.1074/jbc.M310687200

Lagier-Tourenne, C., Polymenidou, M., Hutt, K. R., Vu, A. Q., Baughn, M., Huelga, S. C., et al. (2012). Divergent roles of ALS-linked proteins FUS/TLS and TDP43 intersect in processing long pre-mRNAs. Nat. Neurosci. 15, 1488-1497. doi: 10.1038/nn.3230

Lambert, J. C., Zelenika, D., Hiltunen, M., Chouraki, V., Combarros, O., Bullido, M. J., et al. (2011). Evidence of the association of BIN1 and PICALM with the AD risk in contrasting European populations. Neurobiol. Aging 32, 756.e11-756.e55. doi: 10.1016/j.neurobiolaging.2010.11.022

LaPointe, N. E., Morfini, G., Pigino, G., Gaisina, I. N., Kozikowski, A. P., Binder, L I., et al. (2009). The amino terminus of tau inhibits kinesin-dependent axonal transport: implications for filament toxicity. J. Neurosci. Res. 87, 440-451. doi: 10.1002/jnr.21850

Lasagna-Reeves, C. A., Castillo-Carranza, D. L., Sengupta, U., Guerrero-Munoz, M. J., Kiritoshi, T., Neugebauer, V., et al. (2012). Alzheimer brain-derived tau oligomers propagate pathology from endogenous tau. Sci. Rep. 2, 700. doi: 10.1038/srep00700

La Spada, A. R., and Taylor, J. P. (2010). Repeat expansion disease: progress and puzzles in disease pathogenesis. Nat. Rev. Genet. 11, 247-258. doi: 10.1038/nrg2748

Laurie, D. J., and Seeburg, P. H. (1994). Regional and developmental heterogeneity in splicing of the rat brain NMDAR1 mRNA. J. Neurosci. 14, 3180-3194.

Leboucher, A., Laurent, C., Fernandez-Gomez, F. J., Burnouf, S., Troquier, L., Eddarkaoui, S., et al. (2013). Detrimental effects of diet-induced obesity on tau pathology are independent of insulin resistance in tau transgenic mice. Diabetes 62, 1681-1688. doi: 10.2337/db12-0866

Lee, J. E., and Cooper, T. A. (2009). Pathogenic mechanisms of myotonic dystrophy. Biochem. Soc. Trans. 37, 1281-1286. doi: 10.1042/BST0371281

Lefebvre, S., Burglen, L., Reboullet, S., Clermont, O., Burlet, P., Viollet, L., et al. (1995). Identification and characterization of a spinal muscular atrophydetermining gene. Cell 80, 155-165. doi: 10.1016/0092-8674(95)90460-3

Leprince, C., Romero, F., Cussac, D., Vayssiere, B., Berger, R., Tavitian, A., et al. (1997). A new member of the amphiphysin family connecting endocytosis and signal transduction pathways. J. Biol. Chem. 272, 15101-15105. doi: 10.1074/jbc.272.24.15101

Leroy, O., Dhaenens, C. M., Schraen-Maschke, S., Belarbi, K., Delacourte, A., Andreadis, A., et al. (2006a). ETR-3 represses Tau exons 2/3 inclusion, a splicing event abnormally enhanced in myotonic dystrophy type I. J. Neurosci. Res. 84, 852-859. doi: 10.1002/jnr.20980

Leroy, O., Wang, J., Maurage, C. A., Parent, M., Cooper, T., Buee, L., et al. (2006b). Brain-specific change in alternative splicing of Tau exon 6 in myotonic dystrophy type 1. Biochim. Biophys. Acta 1762, 460-467. doi: 10.1016/j.bbadis.2005.12.003

Li, W., and Lee, V. M. (2006). Characterization of two VQIXXK motifs for tau fibrillization in vitro. Biochemistry 45, 15692-15701. doi: 10.1021/bi061422+

Li, Z. G., Zhang, W., and Sima, A. A. (2007). Alzheimer-like changes in rat models of spontaneous diabetes. Diabetes 56, 1817-1824. doi: 10.2337/db07-0171

Lin, X., Miller, J. W., Mankodi, A., Kanadia, R. N., Yuan, Y., Moxley, R. T., et al. (2006). Failure of MBNL1-dependent post-natal splicing transitions in myotonic dystrophy. Hum. Mol. Genet. 15, 2087-2097. doi: 10.1093/hmg/ddl132

Ling, S. C., Albuquerque, C. P., Han, J. S., Lagier-Tourenne, C., Tokunaga, S., Zhou, H., et al. (2010). ALS-associated mutations in TDP-43 increase its stability and promote TDP-43 complexes with FUS/TLS. Proc. Natl. Acad. Sci. U.S.A. 107, 13318-13323. doi: 10.1073/pnas.1008227107

Liquori, C. L., Ricker, K., Moseley, M. L., Jacobsen, J. F., Kress, W., Naylor, S. L., et al. (2001). Myotonic dystrophy type 2 caused by a CCTG expansion in intron 1 of ZNF9. Science 293, 864-867. doi: 10.1126/science.1062125

Logue, M. W., Schu, M., Vardarajan, B. N., Buros, J., Green, R. C., Go, R. C., et al. (2011). A comprehensive genetic association study of Alzheimer disease 
in African Americans. Arch. Neurol. 68, 1569-1579. doi: 10.1001/archneurol.2011.646

Lotti, F., Imlach, W. L., Saieva, L., Beck, E. S., Hao le, T, Li, D. K., et al. (2012). An SMN-dependent U12 splicing event essential for motor circuit function. Cell 151, 440-454. doi: 10.1016/j.cell.2012.09.012

Luo, M. H., Leski, M. L., and Andreadis, A. (2004a). Tau isoforms which contain the domain encoded by exon 6 and their role in neurite elongation. J. Cell. Biochem. 91, 880-895. doi: 10.1002/jcb.20029

Luo, M. H., Tse, S. W., Memmott, J., and Andreadis, A. (2004b). Novel isoforms of tau that lack the microtubule-binding domain. J. Neurochem. 90, 340-351. doi: 10.1111/j.1471-4159.2004.02508.x

Machuca-Tzili, L., Brook, D., and Hilton-Jones, D. (2005). Clinical and molecular aspects of the myotonic dystrophies: a review. Muscle Nerve 32, 1-18. doi: 10.1002/mus.20301

Mahadevan, M., Tsilfidis, C., Sabourin, L., Shutler, G., Amemiya, C., Jansen, G., et al. (1992). Myotonic dystrophy mutation: an unstable CTG repeat in the $3^{\prime}$ untranslated region of the gene. Science 255, 1253-1255. doi: 10.1126/science. 1546325

Malloy, P., Mishra, S. K., and Adler, S. H. (1990). Neuropsychological deficits in myotonic muscular dystrophy. J. Neurol. Neurosurg. Psychiatr. 53, 1011-1013. doi: 10.1136/jnnp.53.11.1011

Mandelkow, E. M., and Mandelkow, E. (2012). Biochemistry and cell biology of tau protein in neurofibrillary degeneration. Cold Spring Harb. Perspect. Med. 2, a006247. doi: 10.1101/cshperspect.a006247

Mandelkow, E. M., Thies, E., Trinczek, B., Biernat, J., and Mandelkow, E. (2004). MARK/PAR1 kinase is a regulator of microtubule-dependent transport in axons. J. Cell Biol. 167, 99-110. doi: 10.1083/jcb.200401085

Marteyn, A., Maury, Y., Gauthier, M. M., Lecuyer, C., Vernet, R., Denis, J. A., et al. (2011). Mutant human embryonic stem cells reveal neurite and synapse formation defects in type 1 myotonic dystrophy. Cell Stem Cell 8, 434-444. doi: 10.1016/j.stem.2011.02.004

Martin, C. L., Duvall, J. A., Ilkin, Y., Simon, J. S., Arreaza, M. G., Wilkes, K., et al. (2007). Cytogenetic and molecular characterization of A2BP1/FOX1 as a candidate gene for autism. Am. J. Med. Genet. B Neuropsychiatr. Genet. 144B, 869-876. doi: 10.1002/ajmg.b.30530

Martorell, L., Monckton, D. G., Gamez, J., Johnson, K. J., Gich, I., Lopez De Munain, A., et al. (1998). Progression of somatic CTG repeat length heterogeneity in the blood cells of myotonic dystrophy patients. Hum. Mol. Genet. 7, 307-312. doi: $10.1093 / \mathrm{hmg} / 7.2 .307$

Mastroyiannopoulos, N. P., Shammas, C., and Phylactou, L. A. (2010). Tackling the pathogenesis of RNA nuclear retention in myotonic dystrophy. Biol. Cell 102, 515-523. doi: 10.1042/BC20100040

Maurage, C. A., Udd, B., Ruchoux, M. M., Vermersch, P., Kalimo, H., Krahe, R., et al. (2005). Similar brain tau pathology in DM2/PROMM and DM1/Steinert disease. Neurology 65, 1636-1638. doi: 10.1212/01.wnl.0000184585.93864.4e

McVicker, D. P., Chrin, L. R., and Berger, C. L. (2011). The nucleotide-binding state of microtubules modulates kinesin processivity and the ability of Tau to inhibit kinesin-mediated transport. J. Biol. Chem. 286, 42873-42880. doi: 10.1074/jbc.M111.292987

Meola, G., Sansone, V., Perani, D., Colleluori, A., Cappa, S., Cotelli, M., et al. (1999). Reduced cerebral blood flow and impaired visual-spatial function in proximal myotonic myopathy. Neurology 53, 1042-1050. doi: 10.1212/WNL.53.5.1042

Meola, G., Sansone, V., Perani, D., Scarone, S., Cappa, S., Dragoni, C., et al. (2003). Executive dysfunction and avoidant personality trait in myotonic dystrophy type 1 (DM-1) and in proximal myotonic myopathy (PROMM/DM-2). Neuromuscul. Disord. 13, 813-821. doi: 10.1016/S0960-8966(03)00137-8

Miller, J. W., Urbinati, C. R., Teng-Umnuay, P., Stenberg, M. G., Byrne, B. J., Thornton, C. A., et al. (2000). Recruitment of human muscleblind proteins to $(\mathrm{CUG})(\mathrm{n})$ expansions associated with myotonic dystrophy. EMBO J. 19, 4439-4448. doi: 10.1093/emboj/19.17.4439

Mills, J. D., and Janitz, M. (2012). Alternative splicing of mRNA in the molecular pathology of neurodegenerative diseases. Neurobiol. Aging 33, 1012.e11-1012.e24. doi: 10.1016/j.neurobiolaging.2011.10.030

Minnerop, M., Luders, E., Specht, K., Ruhlmann, J., Schneider-Gold, C., Schroder, R., et al. (2008). Grey and white matter loss along cerebral midline structures in myotonic dystrophy type 2. J. Neurol. 255, 1904-1909. doi: 10.1007/s00415008-0997-1
Minnerop, M., Weber, B., Schoene-Bake, J. C., Roeske, S., Mirbach, S., Anspach, C., et al. (2011). The brain in myotonic dystrophy 1 and 2: evidence for a predominant white matter disease. Brain 134, 3530-3546. doi: 10.1093/brain/awr299

Morgan, K. (2011). The three new pathways leading to Alzheimer's disease. Neuropathol. Appl. Neurobiol. 37, 353-357. doi: 10.1111/j.13652990.2011.01181.x

Moseley, M. L., Zu, T., Ikeda, Y., Gao, W., Mosemiller, A. K., Daughters, R. S., et al. (2006). Bidirectional expression of CUG and CAG expansion transcripts and intranuclear polyglutamine inclusions in spinocerebellar ataxia type 8. Nat. Genet. 38, 758-769. doi: 10.1038/ng1827

Mosthaf, L., Vogt, B., Haring, H. U., and Ullrich, A. (1991). Altered expression of insulin receptor types A and B in the skeletal muscle of non-insulin-dependent diabetes mellitus patients. Proc. Natl. Acad. Sci. U.S.A. 88, 4728-4730. doi: 10.1073/pnas.88.11.4728

Moxley, R. T., Corbett, A. J., Minaker, K. L., and Rowe, J. W. (1984). Whole body insulin resistance in myotonic dystrophy. Ann. Neurol. 15, 157-162. doi: 10.1002/ana.410150208

Mukrasch, M. D., Bibow, S., Korukottu, J., Jeganathan, S., Biernat, J., Griesinger, C., et al. (2009). Structural polymorphism of 441-residue tau at single residue resolution. PLoS Biol. 7:e34. doi: 10.1371/journal.pbio.1000034

Mulot, S. F., Hughes, K., Woodgett, J. R., Anderton, B. H., and Hanger, D. P. (1994). PHF-tau from Alzheimer's brain comprises four species on SDS-PAGE which can be mimicked by in vitro phosphorylation of human brain tau by glycogen synthase kinase-3 beta. FEBS Lett. 349, 359-364. doi: 10.1016/00145793(94)00702-0

Naka, H., Imon, Y., Ohshita, T., Honjo, K., Kitamura, T., Mimori, Y., et al. (2002). Magnetization transfer measurements of cerebral white matter in patients with myotonic dystrophy. J. Neurol. Sci. 193, 111-116. doi: 10.1016/S0022510X(01)00652-9

Nakamori, M., Sobczak, K., Puwanant, A., Welle, S., Eichinger, K., Pandya, S., et al. (2013). Splicing biomarkers of disease severity in myotonic dystrophy. Ann. Neurol. doi: 10.1002/ana.23992. [Epub ahead of print].

Nakamori, M., Takahashi, T., Yamazaki, Y., Kurashige, T., Yamawaki, T., and Matsumoto, M. (2012). Cyclin-dependent kinase 5 immunoreactivity for granulovacuolar degeneration. Neuroreport 23, 867-872. doi: 10.1097/WNR.0b013e328358720b

Nakaya, T., Alexiou, P., Maragkakis, M., Chang, A., and Mourelatos, Z. (2013). FUS regulates genes coding for RNA-binding proteins in neurons by binding to their highly conserved introns. RNA 19, 498-509. doi: 10.1261/rna.0378 04.112

Noguchi, M., Yoshita, M., Matsumoto, Y., Ono, K., Iwasa, K., and Yamada, M. (2005). Decreased beta-amyloid peptide42 in cerebrospinal fluid of patients with progressive supranuclear palsy and corticobasal degeneration. J. Neurol. Sci. 237, 61-65. doi: 10.1016/j.jns.2005.05.015

Norgren, S., Zierath, J., Galuska, D., Wallberg-Henriksson, H., and Luthman, H. (1993). Differences in the ratio of RNA encoding two isoforms of the insulin receptor between control and NIDDM patients. The RNA variant without Exon 11 predominates in both groups. Diabetes 42, 675-681. doi: 10.2337/diab.42.5.675

Norgren, S., Zierath, J., Wedell, A., Wallberg-Henriksson, H., and Luthman, H. (1994). Regulation of human insulin receptor RNA splicing in vivo. Proc. Natl. Acad. Sci. U.S.A. 91, 1465-1469. doi: 10.1073/pnas.91.4.1465

Novelli, G., Gennarelli, M., Zelano, G., Pizzuti, A., Fattorini, C., Caskey, C. T., et al. (1993). Failure in detecting mRNA transcripts from the mutated allele in myotonic dystrophy muscle. Biochem. Mol. Biol. Int. 29, 291-297.

Okamoto, K., Hirai, S., Iizuka, T., Yanagisawa, T., and Watanabe, M. (1991). Reexamination of granulovacuolar degeneration. Acta Neuropathol. 82, 340-345. doi: 10.1007/BF00296544

Ono, S., Kurisaki, H., Sakuma, A., and Nagao, K. (1995). Myotonic dystrophy with alveolar hypoventilation and hypersomnia: a clinicopathological study. J. Neurol. Sci. 128, 225-231. doi: 10.1016/0022-510X(94)00244-I

Orozco, D., Tahirovic, S., Rentzsch, K., Schwenk, B. M., Haass, C., and Edbauer, D. (2012). Loss of fused in sarcoma (FUS) promotes pathological Tau splicing. EMBO Rep. 13, 759-764. doi: 10.1038/embor.2012.90

Ota, M., Sato, N., Ohya, Y., Aoki, Y., Mizukami, K., Mori, T., et al. (2006). Relationship between diffusion tensor imaging and brain morphology in patients with myotonic dystrophy. Neurosci. Lett. 407, 234-239. doi: 10.1016/j.neulet.2006.08.077 
Otten, A. D., and Tapscott, S. J. (1995). Triplet repeat expansion in myotonic dystrophy alters the adjacent chromatin structure. Proc. Natl. Acad. Sci. U.S.A. 92, 5465-5469. doi: 10.1073/pnas.92.12.5465

Otto, M., Esselmann, H., Schulz-Shaeffer, W., Neumann, M., Schroter, A., Ratzka, P., et al. (2000). Decreased beta-amyloid1-42 in cerebrospinal fluid of patients with Creutzfeldt-Jakob disease. Neurology 54, 1099-1102. doi: 10.1212/WNL.54.5.1099

Oyamada, R., Hayashi, M., Katoh, Y., Tsuchiya, K., Mizutani, T., Tominaga, I., et al. (2006). Neurofibrillary tangles and deposition of oxidative products in the brain in cases of myotonic dystrophy. Neuropathology 26, 107-114. doi: 10.1111/j.1440-1789.2006.00662.x

Papon, M. A., El Khoury, N. B., Marcouiller, F., Julien, C., Morin, F., Bretteville, A., et al. (2013). Deregulation of protein phosphatase 2A and hyperphosphorylation of tau protein following onset of diabetes in NOD mice. Diabetes 62 609-617. doi: 10.2337/db12-0187

Paul, S., Dansithong, W., Jog, S. P., Holt, I., Mittal, S., Brook, J. D., et al. (2011). Expanded CUG repeats Dysregulate RNA splicing by altering the stoichiometry of the muscleblind 1 complex. J. Biol. Chem. 286, 38427-38438. doi: 10.1074/jbc.M111.255224

Pellizzoni, L., Yong, J., and Dreyfuss, G. (2002). Essential role for the SMN complex in the specificity of snRNP assembly. Science 298, 1775-1779. doi: 10.1126/science. 1074962

Peric, S., Mandic-Stojmenovic, G., Markovic, I., Stefanova, E., Ilic, V., Parojcic, A., et al. (2013a). Cerebrospinal fluid biomarkers of neurodegeneration in patients with juvenile and classic myotonic dystrophy type 1. Eur. J. Neurol. doi: 10.1111/ene.12237. [Epub ahead of print].

Peric, S., Stojanovic, V. R., Nikolic, A., Kacar, A., Basta, I., Pavlovic, S., et al. (2013b). Peripheral neuropathy in patients with myotonic dystrophy type 1. Neurol. Res. 35, 331-335. doi: 10.1179/1743132812Y.0000000144

Perseghin, G., Comola, M., Scifo, P., Benedini, S., De Cobelli, F., Lanzi, R., et al. (2004). Postabsorptive and insulin-stimulated energy and protein metabolism in patients with myotonic dystrophy type 1. Am. J. Clin. Nutr. 80, 357-364.

Philips, A. V., Timchenko, L. T., and Cooper, T. A. (1998). Disruption of splicing regulated by a CUG-binding protein in myotonic dystrophy. Science 280 737-741. doi: 10.1126/science.280.5364.737

Piazzon, N., Rage, F., Schlotter, F., Moine, H., Branlant, C., and Massenet, S. (2008). In vitro and in cellulo evidences for association of the survival of motor neuron complex with the fragile X mental retardation protein. J. Biol. Chem. 283, 5598-5610. doi: 10.1074/jbc.M707304200

Planel, E., Tatebayashi, Y., Miyasaka, T., Liu, L., Wang, L., Herman, M., et al. (2007). Insulin dysfunction induces in vivo tau hyperphosphorylation through distinct mechanisms. J. Neurosci. 27, 13635-13648. doi: 10.1523/JNEUROSCI.394907.2007

Polymenidou, M., Lagier-Tourenne, C., Hutt, K. R., Huelga, S. C., Moran, J., Liang, T. Y., et al. (2011). Long pre-mRNA depletion and RNA missplicing contribute to neuronal vulnerability from loss of TDP-43. Nat. Neurosci. 14, 459-468. doi: 10.1038/nn.2779

Querido, E., Gallardo, F., Beaudoin, M., Menard, C., and Chartrand, P. (2011). Stochastic and reversible aggregation of mRNA with expanded CUG-triplet repeats. J. Cell Sci. 124, 1703-1714. doi: 10.1242/jcs.073270

Rademakers, R., Melquist, S., Cruts, M., Theuns, J., Del-Favero, J., Poorkaj, P., et al (2005). High-density SNP haplotyping suggests altered regulation of tau gene expression in progressive supranuclear palsy. Hum. Mol. Genet. 14, 3281-3292. doi: $10.1093 / \mathrm{hmg} / \mathrm{ddi} 361$

Rakocevic Stojanovic, V., Peric, S., Lavrnic, D., Popovic, S., Ille, T., Stevic, Z., et al. (2010). Leptin and the metabolic syndrome in patients with myotonic dystrophy type 1. Acta Neurol. Scand. 121, 94-98. doi: 10.1111/j.1600-0404.2009. 01237.x

Ranum, L. P., and Cooper, T. A. (2006). RNA-mediated neuromuscular disorders. Annu. Rev. Neurosci. 29, 259-277. doi: 10.1146/annurev.neuro.29.051605. 113014

Reger, M. A., Watson, G. S., Green, P. S., Baker, L. D., Cholerton, B., Fishel, M. A., et al. (2008). Intranasal insulin administration dose-dependently modulates verbal memory and plasma amyloid-beta in memory-impaired older adults. J. Alzheimers. Dis. 13, 323-331.

Renoux, A. J., and Todd, P. K. (2012). Neurodegeneration the RNA way. Prog. Neurobiol. 97, 173-189. doi: 10.1016/j.pneurobio.2011.10.006

Renton, A. E., Majounie, E., Waite, A., Simon-Sanchez, J., Rollinson, S., Gibbs, J. R., et al. (2011). A hexanucleotide repeat expansion in C9ORF72 is the cause of chromosome 9p21-linked ALS-FTD. Neuron 72, 257-268. doi: 10.1016/j.neuron.2011.09.010

Rodriguez, J. J., Olabarria, M., Chvatal, A., and Verkhratsky, A. (2009). Astroglia in dementia and Alzheimer's disease. Cell Death Differ. 16, 378-385. doi: 10.1038/cdd.2008.172

Rogelj, B., Easton, L. E., Bogu, G. K., Stanton, L. W., Rot, G., Curk, T., et al. (2012). Widespread binding of FUS along nascent RNA regulates alternative splicing in the brain. Sci. Rep. 2, 603. doi: 10.1038/srep00603

Romeo, V. (2012). Myotonic Dystrophy Type 1 or Steinert's disease. Adv. Exp. Med. Biol. 724, 239-257. doi: 10.1007/978-1-4614-0653-2_18

Romeo, V., Pegoraro, E., Ferrati, C., Squarzanti, F., Soraru, G., Palmieri, A., et al. (2010). Brain involvement in myotonic dystrophies: neuroimaging and neuropsychological comparative study in DM1 and DM2. J. Neurol. 257, 1246-1255. doi: 10.1007/s00415-010-5498-3

Rosenblum, W. I., and Ghatak, N. R. (1979). Lewy bodies in the presence of Alzheimer's disease. Arch. Neurol. 36, 170-171. doi: 10.1001/archneur.1979.00500390088011

Rubinsztein, J. S., Rubinsztein, D. C., Goodburn, S., and Holland, A. J. (1998) Apathy and hypersomnia are common features of myotonic dystrophy. J. Neurol. Neurosurg. Psychiatr. 64, 510-515. doi: 10.1136/jnnp.64.4.510

Rubinsztein, J. S., Rubinsztein, D. C., McKenna, P. J., Goodburn, S., and Holland, A. J. (1997). Mild myotonic dystrophy is associated with memory impairment in the context of normal general intelligence. J. Med. Genet. 34, 229-233. doi: 10.1136/jmg.34.3.229

Rudnicki, D. D., Holmes, S. E., Lin, M. W., Thornton, C. A., Ross, C. A., and Margolis, R. L. (2007). Huntington's disease-like 2 is associated with CUG repeat-containing RNA foci. Ann. Neurol. 61, 272-282. doi: 10.1002/ana.21081

Rumbaugh, G., Prybylowski, K., Wang, J. F., and Vicini, S. (2000). Exon 5 and spermine regulate deactivation of NMDA receptor subtypes. J. Neurophysiol. 83, 1300-1306.

Sahara, N., Maeda, S., Yoshiike, Y., Mizoroki, T., Yamashita, S., Murayama, M., et al. (2007). Molecular chaperone-mediated tau protein metabolism counteracts the formation of granular tau oligomers in human brain. J. Neurosci. Res. 85, 3098-3108. doi: 10.1002/jnr.21417

Sato-Harada, R., Okabe, S., Umeyama, T., Kanai, Y., and Hirokawa, N. (1996). Microtubule-associated proteins regulate microtubule function as the track for intracellular membrane organelle transports. Cell Struct. Funct. 21, 283-295. doi: $10.1247 /$ csf.21.283

Savkur, R. S., Philips, A. V., and Cooper, T. A. (2001). Aberrant regulation of insulin receptor alternative splicing is associated with insulin resistance in myotonic dystrophy. Nat. Genet. 29, 40-47. doi: 10.1038/ng704

Savkur, R. S., Philips, A. V., Cooper, T. A., Dalton, J. C., Moseley, M. L., Ranum, L. P., et al. (2004). Insulin receptor splicing alteration in myotonic dystrophy type 2. Am. J. Hum. Genet. 74, 1309-1313. doi: 10.1086/421528

Schara, U., and Schoser, B. G. (2006). Myotonic dystrophies type 1 and 2: a summary on current aspects. Semin. Pediatr. Neurol. 13, 71-79. doi: 10.1016/j.spen.2006.06.002

Schmitt, H. P. (2005). On the paradox of ion channel blockade and its benefits in the treatment of Alzheimer disease. Med. Hypotheses 65, 259-265. doi 10.1016/j.mehy.2005.03.011

Schoser, B., and Timchenko, L. (2010). Myotonic dystrophies 1 and 2: complex diseases with complex mechanisms. Curr. Genomics 11, 77-90. doi: $10.2174 / 138920210790886844$

Schraen-Maschke, S., Sergeant, N., Dhaenens, C. M., Bombois, S., Deramecourt, V., Caillet-Boudin, M. L., et al. (2008). Tau as a biomarker of neurodegenerative diseases. Biomark. Med. 2, 363-384. doi: 10.2217/17520363.2.4.363

Schweers, O., Schonbrunn-Hanebeck, E., Marx, A., and Mandelkow, E. (1994) Structural studies of tau protein and Alzheimer paired helical filaments show no evidence for beta-structure. J. Biol. Chem. 269, 24290-24297.

Sebat, J., Lakshmi, B., Malhotra, D., Troge, J., Lese-Martin, C., Walsh, T., et al. (2007). Strong association of de novo copy number mutations with autism Science 316, 445-449. doi: 10.1126/science.1138659

Seitz, A., Kojima, H., Oiwa, K., Mandelkow, E. M., Song, Y. H., and Mandelkow, E. (2002). Single-molecule investigation of the interference between kinesin, tau and MAP2c. EMBO J. 21, 4896-4905. doi: 10.1093/emboj/cdf503

Sellier, C., Rau, F., Liu, Y., Tassone, F., Hukema, R. K., Gattoni, R., et al. (2010). Sam68 sequestration and partial loss of function are associated with splicing alterations in FXTAS patients. EMBO J. 29, 1248-1261. doi: 10.1038/emboj.2010.21 
Sergeant, N., Bretteville, A., Hamdane, M., Caillet-Boudin, M. L., Grognet, P., Bombois, S., et al. (2008). Biochemistry of Tau in Alzheimer's disease and related neurological disorders. Expert Rev. Proteomics 5, 207-224. doi: 10.1586/14789450.5.2.207

Sergeant, N., Delacourte, A., and Buee, L. (2005). Tau protein as a differential biomarker of tauopathies. Biochim. Biophys. Acta 1739, 179-197. doi: 10.1016/j.bbadis.2004.06.020

Sergeant, N., Sablonniere, B., Schraen-Maschke, S., Ghestem, A., Maurage, C. A., Wattez, A., et al. (2001). Dysregulation of human brain microtubule-associated tau mRNA maturation in myotonic dystrophy type 1. Hum. Mol. Genet. 10, 2143-2155. doi: 10.1093/hmg/10.19.2143

Seshadri, S., Fitzpatrick, A. L., Ikram, M. A., DeStefano, A. L., Gudnason, V., Boada, M., et al. (2010). Genome-wide analysis of genetic loci associated with Alzheimer disease. JAMA 303, 1832-1840. doi: 10.1001/jama.2010.574

Sesti, G., Marini, M. A., Tullio, A. N., Montemurro, A., Borboni, P., Fusco, A., et al. (1991). Altered expression of the two naturally occurring human insulin receptor variants in isolated adipocytes of non-insulin-dependent diabetes mellitus patients. Biochem. Biophys. Res. Commun. 181, 1419-1424. doi: 10.1016/0006-291X(91)92097-4

Shahpasand, K., Uemura, I., Saito, T., Asano, T., Hata, K., Shibata, K., et al. (2012). Regulation of mitochondrial transport and inter-microtubule spacing by tau phosphorylation at the sites hyperphosphorylated in Alzheimer's disease. J. Neurosci. 32, 2430-2441. doi: 10.1523/JNEUROSCI.5927-11.2012

Shankar, G. M., Bloodgood, B. L., Townsend, M., Walsh, D. M., Selkoe, D. J., and Sabatini, B. L. (2007). Natural oligomers of the Alzheimer amyloid-beta protein induce reversible synapse loss by modulating an NMDA-type glutamate receptor-dependent signaling pathway. J. Neurosci. 27, 2866-2875. doi: 10.1523/JNEUROSCI.4970-06.2007

Shemesh, E., Rudich, A., Harman-Boehm, I., and Cukierman-Yaffe, T. (2012). Effect of intranasal insulin on cognitive function: a systematic review. J. Clin. Endocrinol. Metab. 97, 366-376. doi: 10.1210/jc.2011-1802

Sicot, G., Gourdon, G., and Gomes-Pereira, M. (2011). Myotonic dystrophy, when simple repeats reveal complex pathogenic entities: new findings and future challenges. Hum. Mol. Genet. 20, R116-R123. doi: 10.1093/hmg/ddr343

Simon-Sanchez, J., Dopper, E. G., Cohn-Hokke, P. E., Hukema, R. K., Nicolaou, N., Seelaar, H., et al. (2012). The clinical and pathological phenotype of C9ORF72 hexanucleotide repeat expansions. Brain 135, 723-735. doi: 10.1093/brain/awr353

Sjogren, M., Davidsson, P., Wallin, A., Granerus, A. K., Grundstrom, E., Askmark, H., et al. (2002). Decreased CSF-beta-amyloid 42 in Alzheimer's disease and amyotrophic lateral sclerosis may reflect mismetabolism of beta-amyloid induced by disparate mechanisms. Dement. Geriatr. Cogn. Disord. 13, 112-118. doi: 10.1159/000048642

Smith, P. Y., Delay, C., Girard, J., Papon, M. A., Planel, E., Sergeant, N., et al. (2011). MicroRNA-132 loss is associated with tau exon 10 inclusion in progressive supranuclear palsy. Hum. Mol. Genet. 20, 4016-4024. doi: 10.1093/hmg/ddr330

Soreq, L., Bergman, H., Israel, Z., and Soreq, H. (2012). Exon arrays reveal alternative splicing aberrations in Parkinson's disease leukocytes. Neurodegener. Dis. 10, 203-206. doi: 10.1159/000332598

Souter, S., and Lee, G. (2010). Tubulin-independent tau in Alzheimer's disease and cancer: implications for disease pathogenesis and treatment. Curr. Alzheimer Res. 7, 697-707. doi: 10.2174/156720510793611637

Sreedharan, J., Blair, I. P., Tripathi, V. B., Hu, X., Vance, C., Rogelj, B., et al. (2008). TDP-43 mutations in familial and sporadic amyotrophic lateral sclerosis. Science 319, 1668-1672. doi: 10.1126/science.1154584

Stoothoff, W., Jones, P. B., Spires-Jones, T. L., Joyner, D., Chhabra, E., Bercury, K., et al. (2009). Differential effect of three-repeat and four-repeat tau on mitochondrial axonal transport. J. Neurochem. 111, 417-427. doi: 10.1111/j.14714159.2009.06316.x

Suenaga, K., Lee, K. Y., Nakamori, M., Tatsumi, Y., Takahashi, M. P., Fujimura, H., et al. (2012). Muscleblind-like 1 knockout mice reveal novel splicing defects in the myotonic dystrophy brain. PLoS ONE 7:e33218. doi: 10.1371/journal.pone.0033218

Tanaka, S., Shiojiri, S., Takahashi, Y., Kitaguchi, N., Ito, H., Kameyama, M., et al. (1989). Tissue-specific expression of three types of beta-protein precursor mRNA: enhancement of protease inhibitor-harboring types in Alzheimer's disease brain. Biochem. Biophys. Res. Commun. 165, 1406-1414. doi: 10.1016/0006291X(89)92760-5
Taneja, K. L., McCurrach, M., Schalling, M., Housman, D., and Singer, R. H. (1995). Foci of trinucleotide repeat transcripts in nuclei of myotonic dystrophy cells and tissues. J. Cell Biol. 128, 995-1002. doi: 10.1083/jcb.128.6.995

Thornton, C. A., Wymer, J. P., Simmons, Z., McClain, C., and Moxley, R. T. 3rd. (1997). Expansion of the myotonic dystrophy CTG repeat reduces expression of the flanking DMAHP gene. Nat. Genet. 16, 407-409. doi: 10.1038/ng0897-407

Tollervey, J. R., Curk, T., Rogelj, B., Briese, M., Cereda, M., Kayikci, M., et al. (2011). Characterizing the RNA targets and position-dependent splicing regulation by TDP-43. Nat. Neurosci. 14, 452-458. doi: 10.1038/nn.2778

Trabzuni, D., Wray, S., Vandrovcova, J., Ramasamy, A., Walker, R., Smith, C., et al. (2012). MAPT expression and splicing is differentially regulated by brain region: relation to genotype and implication for tauopathies. Hum. Mol. Genet. 21, 4094-4103. doi: 10.1093/hmg/dds238

Tran, H., Gourrier, N., Lemercier-Neuillet, C., Dhaenens, C. M., Vautrin, A., Fernandez-Gomez, F. J., et al. (2011). Analysis of exonic regions involved in nuclear localization, splicing activity, and dimerization of Muscleblind-like-1 isoforms. J. Biol. Chem. 286, 16435-16446. doi: 10.1074/jbc.M110.194928

Traynelis, S. F., Burgess, M. F., Zheng, F., Lyuboslavsky, P., and Powers, J. L. (1998). Control of voltage-independent zinc inhibition of NMDA receptors by the NR1 subunit. J. Neurosci. 18, 6163-6175.

Traynelis, S. F., Hartley, M., and Heinemann, S. F. (1995). Control of proton sensitivity of the NMDA receptor by RNA splicing and polyamines. Science 268, 873-876. doi: 10.1126/science.7754371

Trinczek, B., Ebneth, A., Mandelkow, E. M., and Mandelkow, E. (1999). Tau regulates the attachment/detachment but not the speed of motors in microtubuledependent transport of single vesicles and organelles. J. Cell. Sci. 112(Pt 14), 2355-2367.

Turner, C., and Hilton-Jones, D. (2010). The myotonic dystrophies: diagnosis and management. J. Neurol. Neurosurg. Psychiatr. 81, 358-367. doi: 10.1136/jnnp.2008.158261

Twine, N. A., Janitz, K., Wilkins, M. R., and Janitz, M. (2011). Whole transcriptome sequencing reveals gene expression and splicing differences in brain regions affected by Alzheimer's disease. PLoS ONE 6:e16266. doi: 10.1371/journal.pone.0016266

Udd, B., and Krahe, R. (2012). The myotonic dystrophies: molecular, clinical, and therapeutic challenges. Lancet Neurol. 11, 891-905. doi: 10.1016/S14744422(12)70204-1

Umeda, T., Yamashita, T., Kimura, T., Ohnishi, K., Takuma, H., Ozeki, T., et al. (2013). Neurodegenerative disorder FTDP-17-related tau intron $10+16 \mathrm{C}->$ $\mathrm{T}$ mutation increases tau exon 10 splicing and causes tauopathy in transgenic mice. Am. J. Pathol. 183, 211-225. doi: 10.1016/j.ajpath.2013.03.015

Uryu, K., Nakashima-Yasuda, H., Forman, M. S., Kwong, L. K., Clark, C. M., Grossman, M., et al. (2008). Concomitant TAR-DNA-binding protein 43 pathology is present in Alzheimer disease and corticobasal degeneration but not in other tauopathies. J. Neuropathol. Exp. Neurol. 67, 555-564. doi: 10.1097/NEN.0b013e31817713b5

Vance, C., Rogelj, B., Hortobagyi, T., De Vos, K. J., Nishimura, A. L., Sreedharan, J., et al. (2009). Mutations in FUS, an RNA processing protein, cause familial amyotrophic lateral sclerosis type 6 . Science 323, 1208-1211. doi: 10.1126/science. 1165942

Van Everbroeck, B., Green, A. J., Pals, P., Martin, J. J., and Cras, P. (1999). Decreased levels of Amyloid-beta 1-42 in cerebrospinal fluid of Creutzfeldt-Jakob disease patients. J. Alzheimers. Dis. 1, 419-424.

Vermersch, P., Sergeant, N., Ruchoux, M. M., Hofmann-Radvanyi, H., Wattez, A., Petit, H., et al. (1996). Specific tau variants in the brains of patients with myotonic dystrophy. Neurology 47, 711-717. doi: 10.1212/WNL.47.3.711

Vershinin, M., Carter, B. C., Razafsky, D. S., King, S. J., and Gross, S. P. (2007). Multiple-motor based transport and its regulation by Tau. Proc. Natl. Acad. Sci. U.S.A. 104, 87-92. doi: 10.1073/pnas.0607919104

Vershinin, M., Xu, J., Razafsky, D. S., King, S. J., and Gross, S. P. (2008). Tuning microtubule-based transport through filamentous MAPs: the problem of dynein. Traffic 9, 882-892. doi: 10.1111/j.1600-0854.2008.00741.x

Vielhaber, S., Jakubiczka, S., Gaul, C., Schoenfeld, M. A., Debska-Vielhaber, G., Zierz, S., et al. (2006). Brain $1 \mathrm{H}$ magnetic resonance spectroscopic differences in myotonic dystrophy type 2 and type 1 . Muscle Nerve 34, 145-152. doi: 10.1002/mus.20565

Villa, C., Fenoglio, C., De Riz, M., Clerici, F., Marcone, A., Benussi, L., et al. (2011). Role of hnRNP-A1 and miR-590-3p in neuronal death: genetics and 
expression analysis in patients with Alzheimer disease and frontotemporal lobar degeneration. Rejuvenation Res. 14, 275-281. doi: 10.1089/rej.2010.1123

Von Bergen, M., Barghorn, S., Li, L., Marx, A., Biernat, J., Mandelkow, E. M., et al. (2001). Mutations of tau protein in frontotemporal dementia promote aggregation of paired helical filaments by enhancing local beta-structure. J. Biol. Chem. 276, 48165-48174. doi: 10.1074/jbc.M105196200

Von Bergen, M., Friedhoff, P., Biernat, J., Heberle, J., Mandelkow, E. M., and Mandelkow, E. (2000). Assembly of tau protein into Alzheimer paired helical filaments depends on a local sequence motif ((306)VQIVYK(311)) forming beta structure. Proc. Natl. Acad. Sci. U.S.A. 97, 5129-5134. doi: 10.1073/pnas.97.10.5129

Voss, K., Combs, B., Patterson, K. R., Binder, L. I., and Gamblin, T. C. (2012). Hsp70 alters tau function and aggregation in an isoform specific manner. Biochemistry 51, 888-898. doi: 10.1021/bi2018078

Wang, G. S., Kearney, D. L., De Biasi, M., Taffet, G., and Cooper, T. A. (2007). Elevation of RNA-binding protein CUGBP1 is an early event in an inducible heart-specific mouse model of myotonic dystrophy. J. Clin. Invest. 117, 2802-2811. doi: 10.1172/JCI32308

Weber, Y. G., Roebling, R., Kassubek, J., Hoffmann, S., Rosenbohm, A., Wolf, M., et al. (2010). Comparative analysis of brain structure, metabolism, and cognition in myotonic dystrophy 1 and 2. Neurology 74, 1108-1117. doi: 10.1212/WNL.0b013e3181d8c35f

Wegiel, J., Kaczmarski, W., Barua, M., Kuchna, I., Nowicki, K., Wang, K. C., et al. (2011). Link between DYRK1A overexpression and several-fold enhancement of neurofibrillary degeneration with 3-repeat tau protein in Down syndrome. J. Neuropathol. Exp. Neurol. 70, 36-50. doi: 10.1097/NEN.0b013e318202bfal

Wei, M. L., and Andreadis, A. (1998). Splicing of a regulated exon reveals additional complexity in the axonal microtubule-associated protein tau. J. Neurochem. 70, 1346-1356. doi: 10.1046/j.1471-4159.1998.70041346.x

White, M. C., Gao, R., Xu, W., Mandal, S. M., Lim, J. G., Hazra, T. K., et al. (2010). Inactivation of hnRNP K by expanded intronic AUUCU repeat induces apoptosis via translocation of PKCdelta to mitochondria in spinocerebellar ataxia 10. PLoS Genet. 6:e1000984. doi: 10.1371/journal.pgen.1000984

Wijsman, E. M., Pankratz, N. D., Choi, Y., Rothstein, J. H., Faber, K. M., Cheng, R., et al. (2011). Genome-wide association of familial late-onset Alzheimer's disease replicates BIN1 and CLU and nominates CUGBP2 in interaction with APOE. PLoS Genet. 7:e1001308. doi: 10.1371/journal.pgen.1001308

Wilburn, B., Rudnicki, D. D., Zhao, J., Weitz, T. M., Cheng, Y., Gu, X., et al. (2011). An antisense CAG repeat transcript at JPH3 locus mediates expanded polyglutamine protein toxicity in Huntington's disease-like 2 mice. Neuron 70, 427-440. doi: 10.1016/j.neuron.2011.03.021

Wille, H., Drewes, G., Biernat, J., Mandelkow, E. M., and Mandelkow, E. (1992). Alzheimer-like paired helical filaments and antiparallel dimers formed from microtubule-associated protein tau in vitro. J. Cell Biol. 118, 573-584. doi: 10.1083/jcb.118.3.573

Winblad, S., Hellstrom, P., Lindberg, C., and Hansen, S. (2006a). Facial emotion recognition in myotonic dystrophy type 1 correlates with CTG repeat expansion. J. Neurol. Neurosurg. Psychiatr. 77, 219-223. doi: 10.1136/jnnp.2005.070763

Winblad, S., Lindberg, C., and Hansen, S. (2006b). Cognitive deficits and CTG repeat expansion size in classical myotonic dystrophy type 1 (DM1). Behav. Brain Funct. 2, 16. doi: 10.1186/1744-9081-2-16

Winblad, S., Mansson, J. E., Blennow, K., Jensen, C., Samuelsson, L., and Lindberg, C. (2008). Cerebrospinal fluid tau and amyloid beta42 protein in patients with myotonic dystrophy type 1. Eur. J. Neurol. 15, 947-952. doi: 10.1111/j.14681331.2008.02217.x

Wojciechowska, M., and Krzyzosiak, W. J. (2011). Cellular toxicity of expanded RNA repeats: focus on RNA foci. Hum. Mol. Genet. 20, 3811-3821. doi: $10.1093 / \mathrm{hmg} / \mathrm{ddr} 299$

Wong, J. (2013). Altered expression of RNA splicing proteins in Alzheimer's disease patients: evidence from two microarray studies. Dement. Geriatr. Cogn. Dis. Extra 3, 74-85. doi: 10.1159/000348406

Wong, J., Garner, B., Halliday, G. M., and Kwok, J. B. (2012). Srp20 regulates TrkB pre-mRNA splicing to generate TrkB-Shc transcripts with implications for Alzheimer's disease. J. Neurochem. 123, 159-171. doi: 10.1111/j.14714159.2012.07873.x
Wong, L. J., Ashizawa, T., Monckton, D. G., Caskey, C. T., and Richards, C. S. (1995). Somatic heterogeneity of the CTG repeat in myotonic dystrophy is age and size dependent. Am. J. Hum. Genet. 56, 114-122.

Wozniak, J. R., Mueller, B. A., Bell, C. J., Muetzel, R. L., Lim, K. O., and Day, J. W. (2013). Diffusion tensor imaging reveals widespread white matter abnormalities in children and adolescents with myotonic dystrophy type 1. J. Neurol. 260, 1122-1131. doi: 10.1007/s00415-012-6771-4

Wu, J. Q., Wang, X., Beveridge, N. J., Tooney, P. A., Scott, R. J., Carr, V. J., et al. (2012). Transcriptome sequencing revealed significant alteration of cortical promoter usage and splicing in schizophrenia. PLoS ONE 7:e36351. doi: 10.1371/journal.pone.0036351

Wu, T. Y., and Chen, C. P. (2009). Dual action of memantine in Alzheimer disease: a hypothesis. Taiwan. J. Obstet. Gynecol. 48, 273-277. doi: 10.1016/S10284559(09)60303-X

Yamazaki, Y., Matsubara, T., Takahashi, T., Kurashige, T., Dohi, E., Hiji, M., et al. (2011). Granulovacuolar degenerations appear in relation to hippocampal phosphorylated tau accumulation in various neurodegenerative disorders. PLoS ONE 6:e26996. doi: 10.1371/journal.pone.0026996

Yamazaki, Y., Takahashi, T., Hiji, M., Kurashige, T., Izumi, Y., Yamawaki, T., et al. (2010). Immunopositivity for ESCRT-III subunit CHMP2B in granulovacuolar degeneration of neurons in the Alzheimer's disease hippocampus. Neurosci. Lett. 477, 86-90. doi: 10.1016/j.neulet.2010.04.038

Yang, L., Embree, L. J., Tsai, S., and Hickstein, D. D. (1998). Oncoprotein TLS interacts with serine-arginine proteins involved in RNA splicing. J. Biol. Chem. 273, 27761-27764. doi: 10.1074/jbc.273.43.27761

Yang, Y., Ma, D., Wang, Y., Jiang, T., Hu, S., Zhang, M., et al. (2013). Intranasal insulin ameliorates tau hyperphosphorylation in a rat model of type 2 diabetes. J. Alzheimers. Dis. 33, 329-338. doi: 10.3233/JAD-2012-121294

Yoshimura, N., Otake, M., Igarashi, K., Matsunaga, M., Takebe, K., and Kudo, H. (1990). Topography of Alzheimer's neurofibrillary change distribution in myotonic dystrophy. Clin. Neuropathol. 9, 234-239.

Zhang, W., Liu, H., Han, K., and Grabowski, P. J. (2002). Region-specific alternative splicing in the nervous system: implications for regulation by the RNA-binding protein NAPOR. RNA 8, 671-685. doi: 10.1017/S1355838202027036

Zhang, Z., Lotti, F., Dittmar, K., Younis, I., Wan, L., Kasim, M., et al. (2008). SMN deficiency causes tissue-specific perturbations in the repertoire of snRNAs and widespread defects in splicing. Cell 133, 585-600. doi: 10.1016/j.cell.2008.03.031

Zhong, Q., Congdon, E. E., Nagaraja, H. N., and Kuret, J. (2012). Tau isoform composition influences rate and extent of filament formation. J. Biol. Chem. 287, 20711-20719. doi: 10.1074/jbc.M112.364067

Zu, T., Gibbens, B., Doty, N. S., Gomes-Pereira, M., Huguet, A., Stone, M. D., et al. (2011). Non-ATG-initiated translation directed by microsatellite expansions. Proc. Natl. Acad. Sci. U.S.A. 108, 260-265. doi: 10.1073/pnas. 1013343108

Zukin, R. S., and Bennett, M. V. (1995). Alternatively spliced isoforms of the NMDARI receptor subunit. Trends Neurosci. 18, 306-313. doi: 10.1016/01662236(95)93920-S

Conflict of Interest Statement: The authors declare that the research was conducted in the absence of any commercial or financial relationships that could be construed as a potential conflict of interest.

Received: 29 October 2013; paper pending published: 17 December 2013; accepted: 20 December 2013; published online: 09 January 2014.

Citation: Caillet-Boudin M-L, Fernandez-Gomez F-J, Tran H, Dhaenens C-M, Buee $L$ and Sergeant $N$ (2014) Brain pathology in myotonic dystrophy: when tauopathy meets spliceopathy and RNAopathy. Front. Mol. Neurosci. 6:57. doi: 10.3389/fnmol. 2013.00057

This article was submitted to the journal Frontiers in Molecular Neuroscience. Copyright (c) 2014 Caillet-Boudin, Fernandez-Gomez, Tran, Dhaenens, Buee and Sergeant. This is an open-access article distributed under the terms of the Creative Commons Attribution License (CC BY). The use, distribution or reproduction in other forums is permitted, provided the original author(s) or licensor are credited and that the original publication in this journal is cited, in accordance with accepted academic practice. No use, distribution or reproduction is permitted which does not comply with these terms. 